\title{
Ezrin, a membrane cytoskeleton cross linker protein, as a marker of epithelial damage
}

\section{in asthma}

Man $\mathrm{Jia}^{1^{*}}$, Xiaoyi $\mathrm{Yan}^{1,2^{*}}$, Xinyu Jiang ${ }^{1}$, Yunhui $\mathrm{Wu}^{1}$, Jiayan $\mathrm{Xu}^{1}$, Yaqi Meng ${ }^{1}$, Yi Yang ${ }^{1}$, Xia Shan ${ }^{2}$, Xiuwei Zhang ${ }^{2}$, Shan $\mathrm{Mao}^{3}$, Wei Gu${ }^{3}$, Stelios Pavlidis ${ }^{4}$, Peter J. Barnes ${ }^{5}$, Ian M. Adcock $^{5}$, Mao Huang ${ }^{1}$, Xin Yao ${ }^{1}$

${ }^{1}$ Department of Respiratory \& Critical Care Medicine, The First Affiliated Hospital of Nanjing Medical University, 300 Guangzhou Road, Nanjing 210029, China; ${ }^{2}$ Department of Respiratory Medicine, Nanjing Jiangning People's Hospital, Nanjing 210029, China; ${ }^{3}$ Department of Respiratory Medicine, Nanjing First Hospital, Nanjing 210029, China; ${ }^{4}$ Data Science Institute, Imperial College London, Dovehouse Street, London SW3 6LY, U.K; ${ }^{5}$ Airway Disease Section, National Heart and Lung Institute, Faculty of Medicine, Imperial College London, Dovehouse Street, London SW3 6LY, U.K.

*These authors contributed equally to this work.

Corresponding author: Xin Yao, Department of Respiratory \& Critical Care Medicine, The First Affiliated Hospital of Nanjing Medical University, 300 Guangzhou Road, Nanjing 210029, China; E-mail: yaoxin@njmu.edu.cn.

\section{Author contributions}

Man Jia, Ian M Adcock and Xin Yao designed this study; Xia Shan, Xiuwei Zhang, Shan Mao and Wei Gu recruited the patients; Man Jia, Xinyu Jiang and Yi Yang collected EBC and serum samples; Man Jia, Xiaoyi Yan and Jiayan Xu performed the animal experiments; Man Jia, Yunhui Wu and Yaqi Meng performed in vitro experiments; Man Jia, Xiaoyi Yan and 
Stelios Pavlidis performed the analysis of data and interpretation. Man Jia wrote the manuscript; Xin Yao, Mao Huang, Ian M Adcock and Peter J Barnes critically revised the manuscript. All authors read and approved the final paper.

\section{Funding}

This work was supported by the National Natural Science Foundation of China [grant numbers 81070025, 81470237], the Jiangsu Health Promotion Project [grant number ZDRCA2016020], the Priority Academic Program Development of Jiangsu Higher Education Institutions [grant number JX10231802] and the Jiangsu Senior Personnel Fostering Project [grant number LGY2016008]. IMA and PJB were supported by Wellcome Trust grant 093080/Z/10/Z

\section{At a glance commentary}

Scientific Knowledge on the Subject: Bronchial epithelial cell damage occurs in patients with bronchial asthma. However, the underlying molecular mechanisms of interleukin-13 (IL-13) induced epithelial damage in asthma are unclear.

What This Study Adds to the Field: This study shows that ezrin levels were decreased in EBC and serum of asthmatics and was negatively related to lung function, which might be a potential biomarker of asthma control. The expression of ezrin was down-regulated by IL-13 and may be the cause of defective epithelial barrier function in asthma.

This article has an online data supplement, which is accessible from this issue's table of content online at www.atsjournals.org. 


\begin{abstract}
Rationale: Bronchial epithelial cell damage occurs in patients with bronchial asthma. Ezrin, a membrane-cytoskeleton protein, maintains cellular morphology and intercellular adhesion and protects the barrier function of epithelial cells.

Objectives: To study the role of ezrin in bronchial epithelial cells injury and correlate its expression with asthma severity.

Methods: Levels of ezrin were measured in exhaled breath condensate (EBC) and serum in asthma patients and bronchoalveolar lavage fluid (BALF) from a mouse model of asthma by ELISA. The regulation of IL-13 on ezrin protein levels was studied in primary bronchial epithelial cells (PBECs). Ezrin knockdown using shRNA was studied in human bronchial epithelial 16HBE cells.
\end{abstract}

Results: Ezrin levels were decreased in asthmatic EBC (392.7 \pm 34.99 vs $150.5 \pm 10.22$ pg/ml, $\mathrm{p}<0.0001)$ and serum $(700.7 \pm 55.59$ vs $279.2 \pm 25.83 \mathrm{pg} / \mathrm{ml}, \mathrm{p}<0.0001)$ compared to normal subjects. Levels were much lower in uncontrolled $(\mathrm{p}<0.001)$ and partly-controlled patients $(p<0.01)$ compared to well-controlled subjects. EBC and serum ezrin levels correlated with lung function in asthma patients and serum ezrin levels were negatively correlated with serum IL-13 and periostin. IL-13-induced down-regulation of ezrin expression in PBECs was significantly attenuated by the JAK2 (Janus tyrosine kinase 2) inhibitor TG101348. Ezrin knockdown changed 16HBE cell morphology, enlarged intercellular spaces and increased their permeability. Ezrin expression was decreased in the lung tissue and BALF of 'asthmatic' mice and negatively correlated with BALF IL-13 level.

Conclusions: Ezrin down-regulation is associated with IL-13-induced epithelial damage and might be a potential biomarker of asthma control.

Keywords: bronchial asthma, bronchial epithelial cells, interleukin-13, biomarker 


\section{Introduction}

Asthma affects at least 300 million people worldwide and more than 250,000 people die of this disease every year [1]. Bronchial asthma is a chronic airway inflammatory disease, involving a variety of cells (including airway structural cells and inflammatory cells) and cytokines [2]. Defective epithelial barrier integrity and abnormal epithelial shedding have been reported in asthma which is important as airway epithelial cells are the first line of defense against inhaled allergens and environmental exposures in asthma [3]. The impaired epithelial barrier may facilitate penetration of environmental allergens, which can subsequently activate innate immune responses and increase asthma severity and susceptibility [4]. Moreover, the damaged bronchial epithelium releases inflammatory and growth factors that acts on airway smooth muscle cells to alter their function which leads to airway hyper-responsiveness [5]. Importantly, the structural changes occur early in asthma pathogenesis, even years before the appearance of asthma symptoms [6].

Epithelial barrier destruction is associated with reduced mucociliary clearance, decreased cell-cell adhesion, increased intercellular space and permeability [4]. These changes may occur, at least in part, due to chronic inflammation. Epithelial cells are a direct target for IL13 [7] which causes a reduction in ciliary beat frequency and in epithelial tight junctions [8] and enhances mucus production [7]. However, the underlying molecular mechanism of IL-13induced airway epithelial damage is still not clear.

Epithelial cell-cell and cell-substrate adhesion are dependent upon intracellular junctions by regulating E-cadherin and $\beta$-catenin and an orderly arrangement of the cytoskeleton [9]. A-kinase anchoring proteins (AKAPs), a family of $>50$ scaffold proteins, have been reported to enhance barrier stabilization by coordinate the stabilizing effect of PKA (protein kinase A) on the cellular barrier [10] and interacting with cadherins [11]. The ERM (ezrin-radixinmoesin) family can also act as AKAPs [12-14] by building and maintaining the epithelial 
barrier via connecting transmembrane proteins to the actin cytoskeleton [15]. Ezrin (AKAP78), as a constituent of microvilli in regions containing densely packed actin filaments [16], was demonstrated to co-precipitate with $\beta$-catenin and E-cadherin [17] in cell-cell and cell-matrix adhesion and regulate tissue architecture by influencing actin assembly [18]. By controlling the localization and function of certain apical membrane proteins, ezrin has been implicated in microvillus formation, epithelial cell structure and polarity [19]. Moreover, loss of ERM protein in Drosophila results in the damage of mucosal barrier function, following the disruption of cellular morphology and the presence of cellular invasion and migration [20]. In addition, ezrin has been detected in exosomes released from human mesothelioma cells, which suggest that ezrin may be secreted through exosomes [21].

We hypothesized that ezrin may be associated with epithelial damage and might be a potential biomarker for patients with asthma. We aimed to examine ezrin expression and function in bronchial epithelial cells, in a murine model of allergic asthma and in asthma patients.

\section{Materials and Methods (Additional detail on the method for making these measurements is provided in an online data supplement) \\ Patient exhaled breath condensate (EBC) and serum collection}

Human EBC and serum samples were collected from respiratory outpatients with asthma of the First Affiliated Hospital of Nanjing Medical University, Nanjing Jiangning People's Hospital and Nanjing First Hospital and community healthy volunteers. The EBC was collected by using an EcoScreen condenser (Jaeger, Wurzburg, Germany) [22]. The diagnosis of bronchial asthma and severity of asthma were based on the Global Initiative for Asthma (GINA) guidelines [23]. All subjects were non-smokers. The clinical characteristics of the patients are shown in Table 1 . We followed-up 6 patients who were treated with the 
combination of low dose ICS (budesonide) and rapid-onset LABA (formoterol) in a single inhaler and recorded their lung function and symptom control. Additional patient serum samples were from the Unbiased Biomarkers for the Prediction of Respiratory Disease Outcomes (U-BIOPRED) study [24]. Our study was approved by the Medical Ethical Committee of the First Affiliated Hospital of Nanjing Medical University (2013-SRFA-037).

\section{Animal experiments}

$\mathrm{BALB} / \mathrm{c}$ mice (6-8 weeks old, $20 \pm 0.7 \mathrm{~g}$ ) were randomly divided into four groups: control, ovalbumin (OVA), anti-IgG +OVA and anti-IL-13 +OVA. Protocols for the OVA-induced acute asthma model as well as an anti-IgG (Cat. No. RD AP132P) and an anti-IL-13 (Cat. No. RD AF-413-NA) (30 $\mu \mathrm{g} /$ mouse) in allergic asthma model were as previously described [25-26] and were summarized in Figure S1A. Lung tissues were fixed with 4\% paraformaldehyde and subsequently embedded in paraffin for immunohistochemistry staining using a rabbit monoclonal anti-ezrin antibody and an anti-E-cadherin antibody (both Cell Signalling Technology Inc., Beverly, MA, USA)(1:100) and a rabbit polyclonal anti-ZO-1 antibody (Proteintech Group Inc, China) (1:100). Haematoxylin and eosin (H\&E) stained fixed lung tissues sections were used to assess inflammation.

\section{Cell culture and lentivirus shRNA gene transfection}

Primary human bronchial epithelial cells (PBECs) (ScienCell Research Laboratories, Carlsbad, CA, USA) and 16HBE cells were cultured as described previously [27-28]. 16HBE Cells were transfected with lentiviruses encoding for a control shRNA or human EzrinshRNA targeting GFP. 


\section{Exosomes isolation and identification}

$16 \mathrm{HBE}$ cell supernatant underwent sequential preparative ultracentrifugation using a Beckman ultracentrifuge as previously described [29]. Particle size distribution of exosomes was analysized by nanoparticle tracking (NTA) by using ZETASIZER Nano ZS apparatus (Malvern Instruments, Worcestershire, UK) and exosomal markers CD9 and CD63 (Abcam, Cambridge, UK) were also examined by Western blotting.

\section{Transmission electron microscopy (TEM)}

Samples (exosomes and ultra-thin sections of mouse lung tissue) were prepared as described previously [29-30] and were photographed under TEM (JEOL-1010, Jeol, Tokyo, Japan).

\section{Enzyme-linked immunosorbent assay (ELISA)}

The levels of IL-4, IL-5, IL-13 (R\&D, Minneapolis, MN, USA) and ezrin in mouse BALF (CSB-EL007914MO, Cusabio, Wuhan, China) and human serum ezrin (SEB297Hu, Cloud Clone Corp, Wuhan, China), IL-13, periostin and IgE were measured by ELISA kit according to the manufacturer's instructions.

\section{Measurement of transepithelial electrical resistance (TER) and epithelial permeability}

TER of the 16HBE cells, grown in 24-well Transwell (Corning Costar, NY, USA) inserts, was measured daily using the Millicell-ERS system (Millipore Co., Bedford, MA, USA) [31]. Paracellular flux across the epithelium was measured using fluorescein isothiocyanate (FITC)-labeled $4 \mathrm{KDa}$ dextran $(0.5 \mathrm{mg} / \mathrm{ml})$ (Sigma-Aldich) added to the upper chamber followed by incubation for $2 \mathrm{~h}$ at $37^{\circ} \mathrm{C}$. 


\section{Statistical analysis}

All data are represented as mean \pm SEM and $\mathrm{P}<0.05$ was considered significant. The statistical analyses were performed using GraphPad Prism software v5.0 (GraphPad Software, Inc., San Diego, California, USA). Experiments with multiple comparisons were evaluated by one-way ANOVA followed by Student-Newman-Keuls post-test or Bonferroni's post-test (normally distributed parameters) and Kruskal-Wallis test (non-normal distributed parameters) for multiple data sets. Comparisons between two groups were performed with an unpaired Student's t test for normally distributed parameters and with Wilcoxon rank-sum test for nonnormal distributed parameters.

\section{Results}

Ezrin expression was decreased in EBC of asthma patients and positively correlated with lung function.

Ezrin concentrations in EBC were significantly reduced in asthma patients $(150.5 \pm 10.22 \mathrm{pg} / \mathrm{ml})$ compared to normal subjects $(392.7 \pm 34.99 \mathrm{pg} / \mathrm{ml})$ (Figure 1A). Ezrin concentrations decreased according to asthma control: well-controlled group $(243.8 \pm 15.36 \mathrm{pg} / \mathrm{ml})$, partly controlled group $(133.6 \pm 9.08 \mathrm{pg} / \mathrm{ml})$, and uncontrolled group $(98.13 \pm 8.38 \mathrm{pg} / \mathrm{ml})$. Subjects with poor symptom control had a 1.92-fold lower level of ezrin in EBC than those with well-controlled asthma (Figure 1A). Ezrin levels in EBC correlated positively with lung function $\left(\mathrm{FEV}_{1}, \mathrm{FEV}_{1} \%, \mathrm{FEV}_{1} / \mathrm{FVC}\right)$ as a measure of airway obstruction (Figure 1B). In a sub-study we found that ezrin EBC levels were increased, accompanying the improvement in lung function seen in 6 patients after treatment with combination therapy (Figure 1C). 


\section{Reduced serum ezrin levels of asthma patients correlate positively with lung function}

\section{and negatively with serum IL-13 and periostin levels.}

The serum levels of ezrin were significantly decreased $(279.2 \pm 25.83 \mathrm{pg} / \mathrm{ml})$ compared to healthy controls $(700.7 \pm 55.59 \mathrm{pg} / \mathrm{ml})$, and successively decreased in well-controlled $(446.1 \pm 35.54 \mathrm{pg} / \mathrm{ml})$, partly controlled $(256.3 \pm 32.35 \mathrm{pg} / \mathrm{ml})$ and uncontrolled asthma $(174.5 \pm 16.73 \mathrm{pg} / \mathrm{ml})$ (Figure 2A). Subjects with poor symptom control had a 3.77-fold lower level of serum ezrin than those with well-controlled asthma. We validated the reduction in ezrin expression in asthma in the U-BIOPRED cohort which demonstrated a significant reduction in ezrin mRNA expression in blood cells in severe asthma compared to healthy control subjects $\left(\mathrm{FDR}=1.59 \times 10^{-5}\right)$ (Figure $\left.2 \mathrm{C}\right)$. Ezrin gene expression was negatively correlated ( $\mathrm{r}=-0.463$, adjusted $\mathrm{p}=3.40228 \mathrm{E}-09)$ with the enrichment score of IL-13 stimulated epithelial cell-derived T2 signature genes in asthmatic (severe, non-severe) patients and healthy subjects (Figure 2D). However, there was no impact of corticosteroid use on ezrin expression in the U-BIOPRED cohort (data not shown). In our study, ezrin levels in serum were positively related to levels of EBC ezrin (Figure $2 \mathrm{~B})$ and lung function $\left(\mathrm{FEV}_{1}, \mathrm{FEV}_{1} \%\right.$, $\mathrm{FEV}_{1} / \mathrm{FVC}$ ) (Figure 2E). The level of serum IgE (2.24 fold) $(959.7 \pm 228.2$ vs $427.8 \pm 59.12$ ng/ml), IL-13 (2.44 fold) $(642.8 \pm 68.05$ vs $263.3 \pm 62.57 \mathrm{pg} / \mathrm{ml})$ and periostin $(2.01$ fold $)$ $(24.41 \pm 0.82$ vs $12.13 \pm 0.68 \mathrm{ng} / \mathrm{ml})$ were increased in asthma patients compared with healthy controls. Serum ezrin was negatively correlated with IL-13 and periostin, while not related to IgE (Figure 2F).

\section{Ezrin is expressed on exosomes secreted by bronchial epithelial cells.}

The electron microscopic images showed vesicles derived from 16HBE supernatant with the characteristic cup-shape morphology of exosomes (Figure 3A). The mean size distribution was $124 \mathrm{~nm}$ and the percentage of particles between $20-200 \mathrm{~nm}$ was $84.3 \%$ (Figure 3B), which 
corresponds with the exosome size. Western blotting analysis was performed on exosome lysates from the culture supernatants. As depicted in Figure 3C, the exosome markers CD63 $(53 \mathrm{KDa})$, and CD9 $(25 \mathrm{KDa})$ proteins were detected. All these results confirm the presence of exosomes in bronchial epithelial cell culture supernatants. We further isolated exosomes derived from supernatant of IL-13-treated 16HBE cells and found ezrin protein was expressed on exosomes and was decreased compared to control group (Figure 3C), which suggest that ezrin is likely to be secreted via exosomes under the in fluence of IL-13.

\section{IL-13 down-regulates ezrin expression in bronchial epithelial cells by the JAK2/STAT6 pathway.}

We examined the effect of the Th2 cytokines IL- 4 and IL-13 and the Th1 cytokine TNF$\alpha$ on ezrin mRNA and protein expression in $16 \mathrm{HBE}$ cells. IL-13 markedly reduced the expression of ezrin mRNA (reduced by $48.2 \%$ ) and protein (reduced by $45.7 \%$ ) whilst a similar effect was seen for IL-4 effects on ezrin mRNA and protein levels (reduced by $41.6 \%$ and $27.4 \%$ respectively) (Figure 4A-B). TNF- $\alpha$ had no significant effect on the ezrin mRNA and enhanced ezrin protein expression at $24 \mathrm{~h}$ only (Figure4A-B). A similar effect of IL-13 on reducing ezrin protein expression was seen in PBECs (Figure 4C).

To explore molecular mechanism for IL-13-mediated ezrin, PBECs were treated with IL13 for 1 h. IL-13 induced phosphorylation of JAK2 (p-JAK2), followed by increase of its downstream p-STAT6 (Signal transducers and activators of transcription 6) nuclear translocation and subsequently leading to inhibition of ezrin protein expression, however, the effect was reversed by pre-treatment of PBECs with the JAK2 inhibitor TG101348 (Figure 4C). This data suggests that IL-13-induced down-regulation of ezrin in bronchial epithelial cells is due, at least in part, to a JAK2/STAT6-dependent pathway. 


\section{Ezrin depletion alters cell morphology and increases cellular permeability.}

To determine whether the decrease in ezrin expression induced by IL-13 was associated with the damage of bronchial epithelial cells, ezrin expression was knocked down in $16 \mathrm{HBE}$ cells using lentiviruses (LV)-shRNA. Ezrin was successfully transfected with lentiviruses encoding GFP (Figure 5A) resulting in knock down of ezrin mRNA (Figure 5A) and protein levels (Figure 5A). Ezrin-shRNA2 was the most effective shRNA with a knockdown efficiency of $80 \%$ for mRNA and $70 \%$ for protein.

Knock down of ezrin using LV-shRNAs1-3 could all result in marked morphological changes in $16 \mathrm{HBE}$ cells. This changed from a typical multilateral paving stone-like appearance to a round or fusiform appearance accompanied by protrusions from the cells (Figure 5B). Furthermore, the TER of bronchial epithelial cells was significantly decreased from $120.1 \pm 2.51$ to $78.21 \pm 2.51 \Omega . \mathrm{cm}^{2}$ and the intercellular space and permeability were increased after ezrin depletion which was similar to that seen with IL-13 treatment. However, these impaired features could be alleviated with TG101348 pre-treatment (Figure 5B-C).

\section{Ezrin expression and epithelial cell-cell adhesion were decreased in a mouse model of asthma and prevented by anti-IL-13 treatment in lung tissue.}

To further confirm the involvement of IL-13 in epithelial damage of allergic asthma, we established an allergic asthma and an anti-IL-13 in allergic asthma model (Supplementary Figure S1). OVA significantly thickened the trachea wall, widened intercellular space and enhanced inflammatory cell infiltration which was attenuated by anti-IL-13 antibody treatment (Figure 6A). The epithelial cell-cell adherence was clearly damaged in the allergic asthma model whilst prophylactic treatment with a neutralizing IL-13 antibody alleviated the destruction of the cellular tight junctions (Figure 6B). In addition, the expression of tight junction (TJs) marker ZO-1 and of the adherens junction (AJs) marker E-cadherin were both 
decreased in the lung of allergic asthma mice (Figure 6A). These changes were not seen in the anti-IL-13 antibody-treated animals (Figure 6A-B).

Ezrin expression was localized to the apical membrane of bronchial epithelial cells and clearly reduced in 'asthma mice' (Figures 6C). Ezrin levels were also suppressed in the BALF of 'asthmatic mice' $(205.9 \pm 34.71 \mathrm{pg} / \mathrm{ml})$ compared to controls $(1099 \pm 166.1 \mathrm{pg} / \mathrm{ml})$ and were negatively correlated with increased BALF IL-13 ( $\mathrm{r}=-0.6374, \mathrm{p}=0.0191)$ (Figure 6D). However, there was no significant difference in BALF ezrin expression between 'asthmatic mice' and anti-IL-13 antibody-treated mice (173.6 $\pm 19.64 \mathrm{pg} / \mathrm{ml})$ (Figure 6D).

\section{Discussion}

We demonstrated that ezrin levels in serum and EBC were reduced in asthma compared to healthy control subjects and were correlated positively with lung function. In contrast, serum ezrin was negatively correlated with serum IL-13 and periostin. We demonstrated that IL-13 down-regulated ezrin levels in airway epithelial cells and that this was mediated by the JAK2/STAT6 signaling pathway. Knockdown of ezrin in bronchial epithelial cells gave a similar effect on epithelial damage, including increased intercellular space and permeability as seen with IL-13 which implicates ezrin in this important aspect of asthma pathogenesis. Moreover, we discovered that ezrin could be secreted from airway epithelial cells via exosomes under the in fluence of IL-13. In an animal model of allergic asthma, OVA challenge resulted in decreased ezrin expression and epithelial cell-cell adhesion in lung tissue and this was prevented by anti-IL-13 treatment. These results indicated that decreased ezrin due to IL-13 may be the cause of defective epithelial barrier in asthma and may be a potential biomarker of asthma airway epithelial cell dysfunction or remodelling.

Ezrin was initially identified as a cross-linker between the plasma membrane and the cortical cytoskeleton [16]. It is highly enriched and colocalizes with actin at the apical surface 
of many types of simple epithelial cells that have microvilli [32-33]. Based on its localization and protein binding activity, ezrin has been implicated in regulating a variety of cellular processes, including cell polarity [34], epithelial morphology [18], cell-cell and cell-substrate adhesion [36], all of which are essential for maintenance of epithelial barrier integrity.

Ezrin protein maintains a dormant, inactive conformation through masking of the interaction between its FERM (Band 4.1, Ezrin, Radixin, Moesin) and the C-terminal domains in the cytoplasm [15]. Activation of ezrin is triggered by phosphorylation at certain residues: threonine residue (Thr567 in Ezrin) through p38 MAPK- and PKC-dependent mechanisms [36-37] or of tyrosine residues (Tyr353 in Ezrin) driven by the JNK/MAPKK7 pathway [38]. JAK2, consisting of a FERM domain and an atypical SH2 (Src homology 2) domain, is an indispensable regulator in IL-13/STAT6 signaling pathways [39]. A previous study also indicated that ezrin may be a downstream target of the receptor tyrosine kinase (RTK) [40]. In our study, down-regulation of ezrin was accompanied by JAK2/STAT6 activation in response to IL-13 and was reversed after using a selective JAK2 inhibitor TG101348 (Fedratinib; SAR302503) [41].

Previous studies have reported that IL-13 may repress ezrin binding to the apical cytoskeleton and thereby suppress ciliary function via a STAT6-mediated attenuation of foxj1 expression [42-43]. Our data extends the mechanisms of IL-13 suppression of ezrin expression and function by indicating a direct transcriptional effect mediated by the JAK2/STAT6 pathway. Thus, IL-13 may control ciliary function by these two processes acting together to control both ezrin expression and function.

IL-13 alters mucociliary differentiation and ciliary beating of human airway epithelial cells, and also increases the proportion of secretary cells [7-8]. We have extended the understanding IL-13 function to show that IL-13-induced epithelial damage was accompanied with paracellular gap formation, decreased cellular tight junction and TER as well as 
increased permeability to fluxes of Dextran in vitro and vivo. Ezrin knockdown gave similar effects to IL-13 which suggests that ezrin may be an important player in IL-13-induced epithelial injury.

Previous studies have demonstrated that IL-13 can influence the release of exosomes from bronchial epithelial cells which are the major source of exosomes in the lungs of asthmatic patients [44]. In addition to human mesothelioma cells [21], ezrin expression on exosome-like vesicles from ram epididymal fluid and boar seminal plasma has been detected [45-46], which indicates that ezrin can be secreted through exosomes. We show here that ezrin could be secreted from bronchial epithelial cells via exosomes and that this was decreased under the influence of IL-13. Furthermore, ezrin levels both in BALF of asthma mice and serum samples of asthma patients were negatively correlated with IL-13, which all suggest that IL-13 may also have an inhibitory effect on secretion of ezrin.

Study has recently showed that the expression of ezrin might be different in pulmonary diseases. The expression of ezrin protein was unaltered in the BALF of COPD patients but was elevated 3-fold in lung cancer patients compared to control subjects [47]. However, in our study serum ezrin was decreased in asthma patients and negatively associated with biomarkers of Th2 airway inflammation periostin [48] and IL-13 [49] which were both increased in our asthma patients. Ezrin gene expression was negatively correlated with the T2 signature [50] derived from IL-13-stimulated epithelial cells. This relationship indicated that ezrin may be a marker of Th2 phenotype that manifests clinical features of asthma. A limitation to this study is that we did not formally measure the Th2 status of all asthmatic patients studied. EBC and serum ezrin both had a negative relationship with lung function and ezrin measurements may be useful in patients where it is not possible to obtain lung function measures [50]. 
There are some limitations to this study. Although anti-IL-13 prevented the changes in ezrin expression in lung tissue and function, this study was performed prophylactically, and the effect of therapeutic intervention is unknown. We believe that ezrin should be considered as a biomarker that can indicate both epithelial injury and control levels in asthma patients. The potential of using ezrin levels to monitor or dictate clinical practice need to be further investigated with appropriately designed prospective studies. Future studies will investigate the mechanism by which ezrin is secreted by exosomes and whether autologous exosomes will enable ezrin to treat epithelial damage. 


\section{Acknowledgements}

We wish to thank Dr. Fang Wang (the principal investigator of the Laboratory of Cardiovascular Disease of First Affiliated Hospital with Nanjing Medical University) and Dr. Jifu Wei (the principal investigator of Research Division of Clinical Pharmacology) for technical support. 


\section{References}

1. Bousquet J, Mantzouranis E, Cruz AA, et al. Uniform definition of asthma severity, control, and exacerbations: document presented for the World Health Organization Consultation on Severe Asthma. J. Allergy Clin. Immunol 2010;126:926-938.

2. Cohn L, Elias JA, Chupp GL. Asthma: mechanisms of disease persistence and progression. Annu Rev Immunol 2004;22:789-815.

3. Holgate ST, Roberts G, Arshad HS, Howarth PH, Davies DE. The role of the airway epithelium and its interaction with environmental factors in asthma pathogenesis. Proc Am Thorac Soc 2009;6:655-659.

4. Xiao C, Puddicombe SM, Field S, Haywood J, Broughton-Head V, Puxeddu I, Haitchi HM, Vernon-Wilson E, Sammut D, Bedke N, Cremin C, Sones J, Djukanović R, Howarth PH, Collins JE, Holgate ST, Monk P, Davies DE. Defective epithelial barrier function in asthma. J Allergy Clin Immunol 2011;128:549-556.

5. Barnes PJ, Cuss FM, Palmer JB. The effect of airway epithelium on smooth muscle contractility in bovine trachea. Br J Pharmacol 1985;86:685-691.

6. Barbato A, Turato G, Baraldo S, Bazzan E, Calabrese F, Panizzolo C, Zanin ME, Zuin R, Maestrelli P, Fabbri LM, Saetta M. Epithelial damage and angiogenesis in the airways of children with asthma. Am J Respir Crit Care Med 2006;174:975-981.

7. Cohn L, Homer RJ, Marinov A, Rankin J, Bottomly K. Induction of airway mucus production By T helper 2 (Th2) cells: a critical role for interleukin 4 in cell recruitment but not mucus production. J Exp Med 1997;186:1737-1747.

8. Laoukili J, Perret E, Willems T, Minty A, Parthoens E, Houcine O, Coste A, Jorissen M, Marano F, Caput D, Tournier F. IL-13 alters mucociliary differentiation and ciliary beating of human respiratory epithelial cells. J Clin Invest 2001;108:1817-1824. 
9. Steed E, Balda MS, Matter K. Dynamics and functions of tight junctions. Trends Cell Biol 2010;20:142-149

10. Schlegel N, Waschke J. VASP is involved in cAMP-mediated Rac 1 activation in microvascular endothelial cells. Am J Physiol Cell Physiol 2009;296:C453-462.

11. Oldenburger A, Poppinga WJ, Kos F, de Bruin HG, Rijks WF, Heijink IH, Timens W, Meurs H, Maarsingh H, Schmidt M. A-kinase anchoring proteins contribute to loss of Ecadherin and bronchial epithelial barrier by cigarette smoke. Am J Physiol Cell Physiol 2014;306:C585-597.

12. Dransfield DT, Bradford AJ, Smith J, Martin M, Roy C, Mangeat PH, Goldenring JR. Ezrin is a cyclic AMP-dependent protein kinase anchoring protein. EMBO J 1997;16:3543.

13. Semenova I, Ikeda K, Ivanov P, Rodionov V. The protein kinase A-anchoring protein moesin is bound to pigment granules in melanophores. Traffic 2009;10:153-160.

14. Deming PB, Campbell SL, Stone JB, Rivard RL, Mercier AL, Howe AK. Anchoring of protein kinase A by ERM (ezrin-radixin-moesin) proteins is required for proper netrin signaling through DCC (deleted in colorectal cancer). J Biol Chem 2015;290:5783-5796.

15. Bretscher A, Reczek D, Berryman M. Ezrin: a protein requiring conformational activation to link microfilaments to the plasma membrane in the assembly of cell surface structures. J Cell Sci 1997;110:3011-3018.

16. Bretscher A. Purification of an 80,000 -dalton protein that is a component of the isolated microvillus cytoskeleton, and its localization in nonmuscle cells. J Cell Biol 1983;97:425432.

17. Fukunaga Y, Liu H, Shimizu M, Komiya S, Kawasuji M, Nagafuchi A. Defining the roles of beta-catenin and plakoglobin in cell-cell adhesion: isolation of betacatenin/plakoglobin-deficient F9 cells. Cell Struct Funct 2005;30:25-34. 
18. Fehon RG, McClatchey AI, Bretscher A. Organizing the cell cortex: the role of ERM proteins. Nat Rev Mol Cell Biol 2010;11:276-287.

19. Saotome I, Curto M, McClatchey AI. Ezrin is essential for epithelial organization and villus morphogenesis in the developing intestine. Dev Cell 2004;6:855-864.

20. Speck O, Hughes SC, Noren NK, Kulikauskas RM, Fehon RG. Moesin functions antagonistically to the Rho pathway to maintain epithelial integrity. Nature $2003 ; 421: 83$ 87.

21. Hegmans JP, Bard MP, Hemmes A, Luider TM, Kleijmeer MJ, Prins JB, Zitvogel L, Burgers SA, Hoogsteden HC, Lambrecht BN. Proteomic analysis of exosomes secreted by human mesothelioma cells. Am J Pathol 2004;164:1807-1815.

22. Carpagnano GE, Foschino-Barbaro MP, Mulé G, Resta O, Tommasi S, Mangia A,Carpagnano F, Stea G, Susca A, Di Gioia G, De Lena M, Paradiso A. 3p microsatellite alterations in exhaled breath condensate from patients with non-small cell lung cancer. Am J Respir Crit Care Med 2005;172:738-744.

23. Reddel HK, Bateman ED, Becker A, Boulet LP, Cruz AA, Drazen JM, et al. A summary of the new GINA strategy: a roadmap to asthma control. Eur Respir J 2015;46:622-639.

24. Shaw DE, Sousa AR, Fowler SJ, Fleming LJ, Roberts G, Corfield J, et al. Clinical and inflammatory characteristics of the European U-BIOPRED adult severe asthma cohort. Eur Respir J 2015;46:1308-1321.

25. Daubeuf F, Frossard N. Acute Asthma Models to Ovalbumin in the Mouse. Curr Protoc Mouse Biol 2013;3:31-37.

26. Yang G, Volk A, Petley T, Emmell E, Giles-Komar J, Shang X, Li J, Das AM, Shealy D, Griswold DE, Li L. Anti-IL-13 monoclonal antibody inhibits airway hyperresponsiveness, inflammation and airway remodeling. Cytokine 2004;28:224-232. 
27. Lordan JL, Bucchieri F, Richter A, Konstantinidis A, Holloway JW, Thornber M, Puddicombe SM, Buchanan D, Wilson SJ, Djukanović R, Holgate ST, Davies DE. Cooperative effects of Th2 cytokines and allergen on normal and asthmatic bronchial epithelial cells. J Immunol 2002;169:407-414.

28. Wang Y, Jia M, Yan X, Cao L, Barnes PJ, Adcock IM, Huang M, Yao X. Increased neutrophil gelatinase-associated lipocalin (NGAL) promotes airway remodelling in chronic obstructive pulmonary disease. Clin Sci (Lond) 2017;131:1147-1159.

29. Théry C, Amigorena S, Raposo G, Clayton A. Isolation and characterization of exosomes from cell culture supernatants and biological fluids. Curr Protoc Cell Biol 2006;3.22.13.22.29.

30. Chen HQ, Yang J, Zhang M, Zhou YK, Shen TY, Chu ZX, Zhang M, Hang XM, Jiang YQ, Qin HL. Lactobacillus plantarum ameliorates colonic epithelial barrier dysfunction by modulating the apical junctional complex and PepT1 in IL-10 knockout mice. Am J Physiol Gastrointest Liver Physiol 2010;299:G1287-1297.

31. Wawrzyniak P, Wawrzyniak M, Wanke K, Sokolowska M, Bendelja K, Rückert B, Globinska A, Jakiela B, Kast JI, Idzko M, Akdis M, Sanak M, Akdis CA. Regulation of bronchial epithelial barrier integrity by type 2 cytokines and histone deacetylases in asthmatic patients. J Allergy Clin Immunol 2017;139:93-103.

32. Ezzell RM, Chafel MM, Matsudaira PT. Differential localization of villin and fimbrin during development of the mouse visceral endoderm and intestinal epithelium. Development 1989;106:407-419.

33. Maunoury R, Robine S, Pringault E, Huet C, Guénet JL, Gaillard JA, Louvard D. Villin expression in the visceral endoderm and in the gut anlage during early mouse embryogenesis. EMBO J 1988;7:3321-3329. 
34. Bretscher A, Edwards K, Fehon RG. ERM proteins and merlin: integrators at the cell cortex. Nat Rev Mol Cell Biol 2002;3:586-599.

35. Hiscox S, Jiang WG. Ezrin regulates cell-cell and cell-matrix adhesion, a possible role with E-cadherin/beta-catenin. J Cell Sci 1999.112 Pt18:3081-3090.

36. Ren L, Hong SH, Cassavaugh J, Osborne T, Chou AJ, Kim SY, Gorlick R, Hewitt SM, Khanna C. The actin-cytoskeleton linker protein ezrin is regulated during osteosarcoma metastasis by PKC. Oncogene 2009;28:792-802.

37. Lan M, Kojima T, Murata M, Osanai M, Takano K, Chiba H, Sawada N. Phosphorylation of ezrin enhances microvillus length via a p38 MAP-kinase pathway in an immortalized mouse hepatic cell line. Exp Cell Res 2006;312:111-120.

38. Parameswaran N, Enyindah-Asonye G, Bagheri N, Shah NB, Gupta N. Spatialcoupling of JNK activation to the B cell antigen receptor by tyrosine-phosphorylated ezrin. J Immunol 2013; 190:2017-2026.

39. Kelly-Welch AE, Hanson EM, Boothby MR, Keegan AD. Interleukin-4 and interleukin13 signaling connections maps. Science 2003;300:1527-1528.

40. Monni R, Haddaoui L, Naba A, Gallais I, Arpin M, Mayeux P, Moreau-Gachelin F. Ezrin is a target for oncogenic Kit mutants in murine erythroleukemia. Blood 2008;111:31633172.

41. Wernig G, Kharas MG, Okabe R, Moore SA, Leeman DS, Cullen DE et al. Efficacy of TG101348, a selective JAK2 inhibitor, in treatment of a murine model of JAK2V617Finduced polycythemia vera. Cancer Cell 2008;13:311-320.

42. Gomperts BN, Kim LJ, Flaherty SA, Hackett BP. IL-13 regulates cilia loss and foxj1 expression in human airway epithelium. Am J Respir Cell Mol Biol. 2007;37:339-346. 
43. Skowron-zwarg M, Boland S, Caruso N, Coraux C, Marano F, Tournier F. Interleukin-13 interferes with CFTR and AQP5 expression and localization during human airway epithelial cell differentiation. Exp Cell Res 2007;313:2695-2702.

44. Kulshreshtha A, Ahmad T, Agrawal A, Ghosh B. Proinflammatory role of epithelial cellderived exosomes in allergic airway inflammation. J Allergy Clin Immunol 2013; 131:1194-1203.

45. Gatti JL, Metayer S, Belghazi M, Dacheux F, Dacheux JL. Identification, proteomic profiling, and origin of ram epididymal fluid exosome-like vesicles. Biol Reprod $2005 ; 72: 1452-1465$.

46. Piehl LL, Fischman ML, Hellman U, Cisale H, Miranda PV. Boar seminal plasma exosomes: effect on sperm function and protein identification by sequencing. Theriogenology 2013;79:1071-1082.

47. Pastor MD, Nogal A, Molina-Pinelo S, Meléndez R, Salinas A, González De la Peña M, Martín-Juan J, Corral J, García-Carbonero R, Carnero A, Paz-Ares L. Identification of proteomic signatures associated with lung cancer and COPD. J Proteomics 2013;89:227237.

48. Matsumoto H. Serum periostin: a novel biomarker for asthma management. Allergol Int 2014;63:153-160.

49. Silkoff PE, Laviolette M, Singh D, FitzGerald JM, Kelsen S, Backer V, Porsbjerg CM, Girodet PO, Berger P, Kline JN, Chupp G, Susulic VS, Barnathan ES, Baribaud F, Loza MJ. Identification of airway mucosal type 2 inflammation by using clinical biomarkers in asthmatic patients. J Allergy Clin Immunol 2017;140:710-719.

50. Cooper BG. An update on contraindications for lung function testing. Thorax 2011; 66:714-723. 


\section{Figure Legends}

Figure1. Ezrin expression was decreased in exhaled breath condensate (EBC) of asthma patients and positively correlated with lung function. (A) Ezrin expression in EBC samples from asthmatic patients $(n=56)$ and healthy control volunteers $(n=19)$ was detected by ELISA. Decreased levels of ezrin were associated with the degree of asthma symptom control according to the asthma control test (ACT) scores. (B) The relationship between ezrin and $\mathrm{FEV}_{1}, \mathrm{FEV}_{1} \%$ and $\mathrm{FEV}_{1} / \mathrm{FVC}, \mathrm{n}=40-47$. (C) Correlation between ezrin EBC levels and $\mathrm{FEV}_{1}, \mathrm{FEV}_{1} / \mathrm{FVC}$ of patients $(\mathrm{n}=6)$ before and after asthma symptom control using analysis of covariance (ANCOVA). The data were analyzed using Wilcoxon rank-sum test and KruskalWallis test in (A), Pearson's Correlation test in (B). Ns (not significant), ${ }^{* *} \mathrm{P}<0.01$ and $* * * \mathrm{p}<0.001$ compared with respective control groups.

Figure 2. Reduced serum ezrin levels of asthma patients correlate positively with lung function and negatively with serum IL-13 and periostin levels. (A) The expression of ezrin in serum was reduced in asthma patients $(n=59)$ compared to healthy controls $(n=18)$. Serum levels of ezrin were decreased according to the degree of asthma control: well-controlled group ( $n=19)$, partly controlled group $(n=13)$, and uncontrolled group $(n=23)$. (B) The correlation between ezrin levels in EBC and in serum $(n=34)$. (C) Ezrin mRNA expression in blood cells in severe asthma compared to healthy control subjects, by cohort (adjusted $\mathrm{p}=0.0022$ ). Graphs are expressed as $\log 2$ intensity robust multi-array average signals. The differences between healthy controls and patients with severe asthma were analyzed using the Benjamini-Hochberg method for adjusted p-value/false discovery rate (FDR). (D) The correlation between EZR expression and T2 signature genes expression in IL-13 stimulated epithelial cells from asthma patients and healthy subjects $(n=147)$. Ezrin gene expression is presented as $\log 2$ intensity robust multi-array average signals and the expression of the IL-13 
signature genes as an Enrichment Score. SAn: severe nonsmoking asthma; SAs: smokers with severe asthma; MMA: mild/moderate nonsmoking asthma; HC: healthy nonsmoking controls. (E) The relation between serum ezrin and $\mathrm{FEV}_{1}, \mathrm{FEV}_{1} \%$ and $\mathrm{FEV}_{1} / \mathrm{FVC}, \mathrm{n}=44-47$. (F) The concentrations of serum IgE (asthma group $n=18$, control group $n=14$ ), IL-13 (asthma group $n=29$, control group $n=13$ ) and periostin (asthma group $n=56$, control group $n=23$ ) were measured using ELISA (upper panels) and their relationships with ezrin were also analyzed (lower panels). Data were quantified and expressed as mean $\pm \mathrm{SD}, * \mathrm{p}<0.05, * * \mathrm{p}<0.01$ and $* * * \mathrm{p}<0.001$ compared to respective controls. The data were analyzed using Wilcoxon ranksum test in (A), IgE and periostin (F), Student's t-test in IL-13 (F), Pearson's Correlation test in (B) and (D-F).

Figure 3. Ezrin is expressed on exosomes secreted by bronchial epithelial cells. (A) Electron-microscopic observation of whole-mounted exosomes purified from 16HBE cells. White arrows indicate exosomes. Scale bar $=1 \mu \mathrm{m}$ and 200nm, respectively. (B) Intensity and size distribution of exosomes derived from 16HBE cells were measured by nanoparticle tracking analysis (NTA). Graph showing the average percentage of particles within 50-350 nm size in exosome. (C) Western blot analysis showed the presence of ezrin as well as exosome markers CD9 and CD63 in exosomes isolated from 16HBE cells (Ctrl) and the IL-13 $(30 \mathrm{ng} / \mathrm{ml})$ treated group (IL-13).

Figure 4. IL-13 down-regulates ezrin expression in bronchial epithelial cells via the JAK2/STAT6 pathway. (A) 16HBE cells were treated with IL-4 (20ng/ml), IL-13 (30ng/ml) and TNF- $\alpha(10 \mathrm{ng} / \mathrm{ml})$ for 6,12 and 24 hours (h), and ezrin mRNA expression was measured by RT-qPCR. (B) 16HBE cells were exposed to IL-4 (20ng/ml), IL-13 (30ng/ml) and TNF- $\alpha$ $(10 \mathrm{ng} / \mathrm{ml})$ for $24,48,72 \mathrm{~h}$, and Ezrin protein production was determined by Western blotting. 
(C) PBECs were stimulated with IL-13 (30ng/ml) for 24, 48, 72h, respectively. Ezrin protein was evaluated by Western blotting. (D) PBECs were pre-treated with the JAK2 inhibitor TG101348 (30nM) for 1h before IL-13 (30ng/ml) stimulation (1h). The total phospho (p)JAK2 protein level as well as p-STAT6 protein in the nucleus were measured by Western blotting. The effect of TG101348 pre-treatment on IL-13-regulated ezrin expression was evaluated by Western blotting. Data are presented as mean \pm SEM of 3 independent experiments using one-way ANOVA followed by Student-Newman-Keuls post hoc analysis. Ns (not significant), ${ }^{*} \mathrm{P}<0.05, * * \mathrm{p}<0.01$ and $* * * \mathrm{P}<0.001$, compared with control (Ctrl).

\section{Figure 5. Ezrin depletion alters cell morphology and increases cellular permeability. (A)} 16HBE cells were transfected with lentiviruses encoding for a control shRNA (Ctrl) or human ezrin-shRNA (EZR-shR1-3) tagged with GFP for 24h, washed and cells examined after a further 48h. GFP was detected by immunofluorescence (original magnification: $400 \times$ magnification; bar: $100 \mu \mathrm{m}), \mathrm{RT}-\mathrm{qPCR}$ and Western blotting. $* * * \mathrm{p}<0.001$ compared with the Ctrl group. (B) Phase contrast images $(100 \times$ and $400 \times)$ of $16 \mathrm{HBE}$ cells treated with control media (Ctrl), transfection control (Ctrl-shR), IL-13(30ng/ml), ezrin-shRNA (EZRshR1-3) and IL-13(30ng/ml) +TG101348 (30nM). White double arrow shows intercellular space enlargement; white single arrow shows cellular protrusions. (C) Assessment of the permeability of the bronchial epithelium based on transepithelial electrical resistance (TER) and FITC-Dextran in control media (Ctrl), transfection control (Ctrl-shR), IL-13 (30ng/ml), Ezrin-shRNA (EZR-shR2) and IL-13(30ng/ml) +TG101348 (30nM) groups. The data were analyzed using one-way ANOVA followed by Student- Newman-Keuls post hoc analysis, ${ }^{*} \mathrm{P}<0.05$ (IL-13 vs control), ${ }^{\#} \mathrm{P}<0.05$ (EZR-shR2 vs Ctrl-shR) in (C); ${ }^{*} \mathrm{P}<0.05,{ }^{*} \mathrm{P}<0.01$ and $* * * \mathrm{p}<0.001$ compared to respective controls. Phase contrast images are representative of those seen in 3 independent experiments. 


\section{Figure 6. Ezrin expression and epithelial cell-cell adhesion were decreased in an} ovalbumin (OVA)-treated allergic mouse model of asthma and restored by anti-IL-13

treatment. (A) H\&E staining of lung tissue in 'asthma' mice (original magnification $\times 400$, black arrow). Representative E-cadherin and ZO-1 immunostaining (brown color) was examined in saline-exposed control mice (control), OVA-treated mice (OVA), OVA+anti-IgG antibody mice (anti-IgG) and ONA+anti-IL-13 antibody treatment mice (anti-IL-13) and was analyzed by Image-proplus6.0 (original magnification $\times 400$, black arrow). (B) Epithelial cellcell adherence was determined by electron microscopy (original magnification $\times 4800$, white arrow). (C) Immunohistochemical analysis of ezrin expression in saline-exposed control mice (control), OVA-treated mice (OVA), OVA+anti-IgG antibody mice (anti-IgG) and ONA+anti-IL-13 antibody mice (anti-IL-13) (original magnification $\times 400$, scale bar $100 \mu \mathrm{m}$, black arrow) and scored (right graph). (D) The concentrations of ezrin in BALF of OVAtreated mice (OVA), OVA+anti-IgG antibody mice (anti-IgG) and OVA+anti-IL-13 antibody treatment mice (anti-IL-13) and IL-13 of asthma mice and controls were measured using an ELISA. The data are presented as mean \pm SEM and were analyzed by Student's t-test (control group, $\mathrm{n}=8-15$; asthma group, $\mathrm{n}=8-17$ ). The correlation between Ezrin and IL-13 in BALF of mice was analyzed by Pearson's Correlation test. Ns (not significant), $* \mathrm{P}<0.05, * * * \mathrm{p}<0.001$ compared to respective controls. 
Table 1. Baseline patient characteristics

\begin{tabular}{|l|c|c|c|}
\hline & Control & Asthma group & P-Value \\
\hline Number & 23 & 61 & \\
\hline Gender & $10 / 13$ & $25 / 36$ & 0.836 \\
\hline Age & $50.88 \pm 1.151$ & $49.35 \pm 1.098$ & 0.6549 \\
\hline BMI ( kg/m $\left.{ }^{2}\right)$ & $24.56 \pm 0.851$ & $24.11 \pm 0.582$ & 0.6886 \\
\hline Smoking (pack years) & 0 & 0 & \\
\hline FEV $\mathbf{1}$ & $2.378 \pm 0.063$ & $1.908 \pm 0.123$ & $0.0354^{*}$ \\
\hline FEV $\mathbf{1} \%$ & $96.25 \pm 2.390$ & $72.45 \pm 3.469$ & $0.0002^{* * *}$ \\
\hline FEV $\mathbf{1} /$ FVC & $75.57 \pm 2.178$ & $66.37 \pm 1.683$ & $0.0022^{* *}$ \\
\hline PEF & $5.023 \pm 0.3377$ & $4.192 \pm 0.2939$ & 0.0976 \\
\hline
\end{tabular}

Data is shown as mean $\pm \mathrm{SD}$.

${ }^{*} \mathrm{p}<0.05, * * \mathrm{P}<0.01$ and $* * * \mathrm{p}<0.001$ compared with control groups.

$\mathrm{BMI}$, body mass index; $\mathrm{FEV}_{1}$, forced expiratory volume in 1 second; $\mathrm{FEV}_{1} \%$, forced expiratory volume in one second; FEV1/FVC, forced expiratory volume in one second to forced vital capacity ratio; PEF, peak expiratory flow. 
Figure 1

A
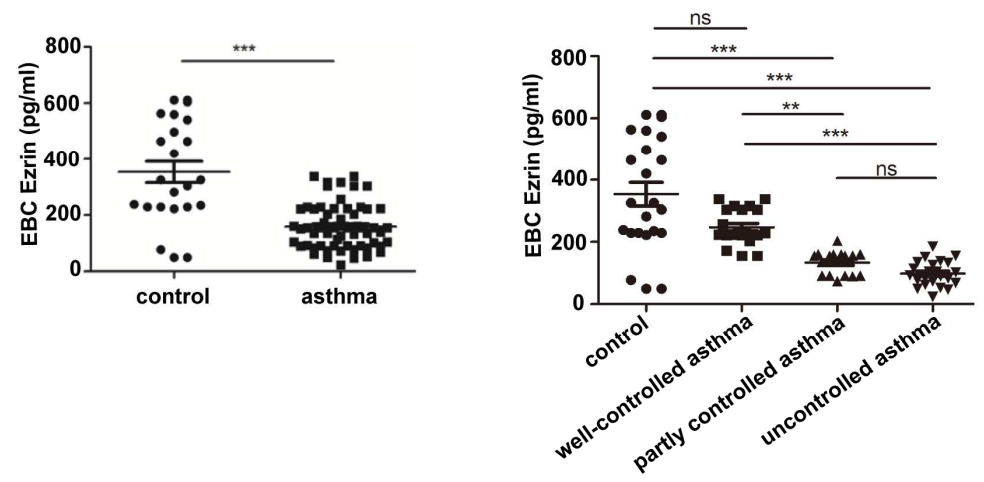

B
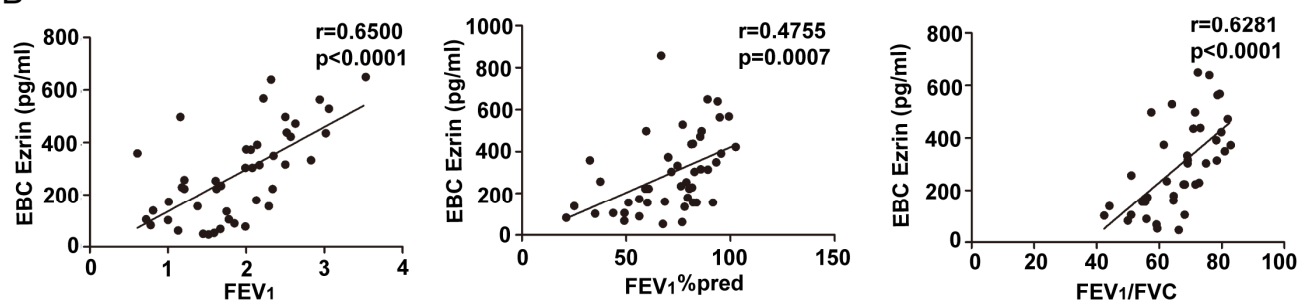

C
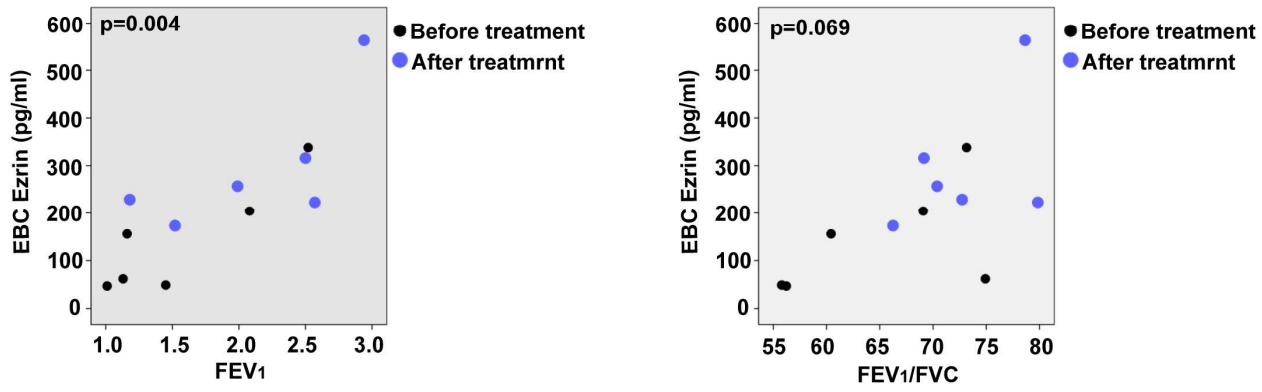
Figure 2

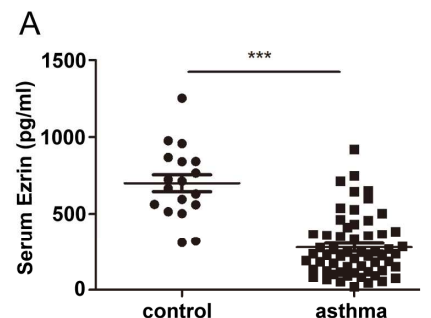

C

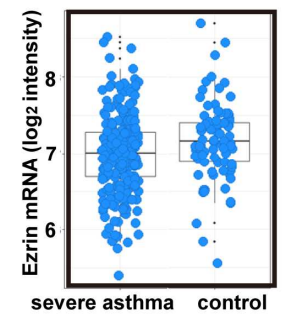

$\mathrm{E}$

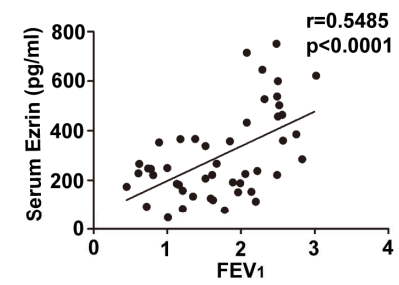

F
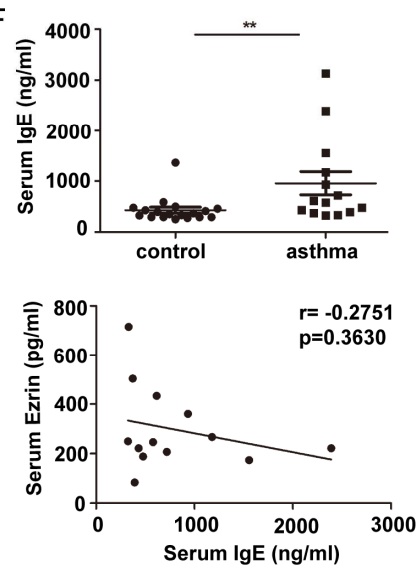

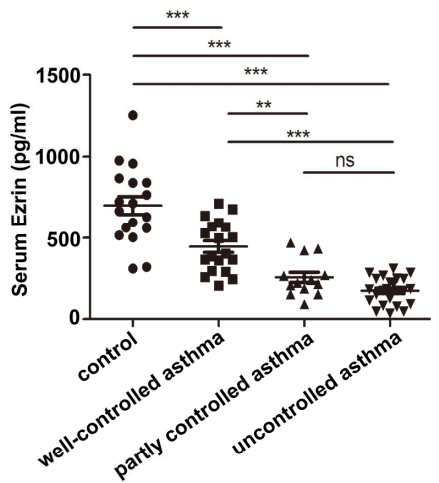

B

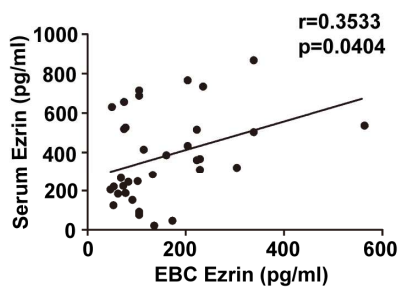

D

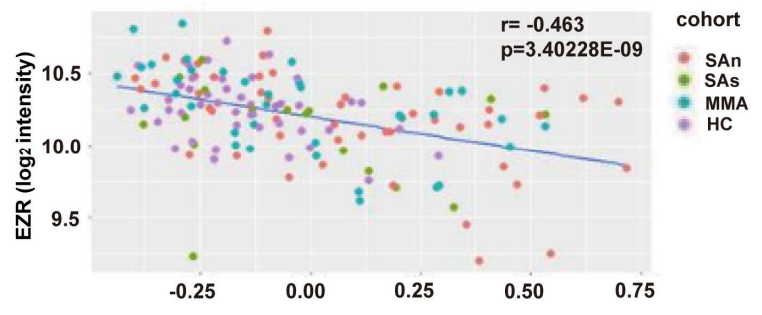

IL-13 in vitro stimulation signature (Enrichment Score)
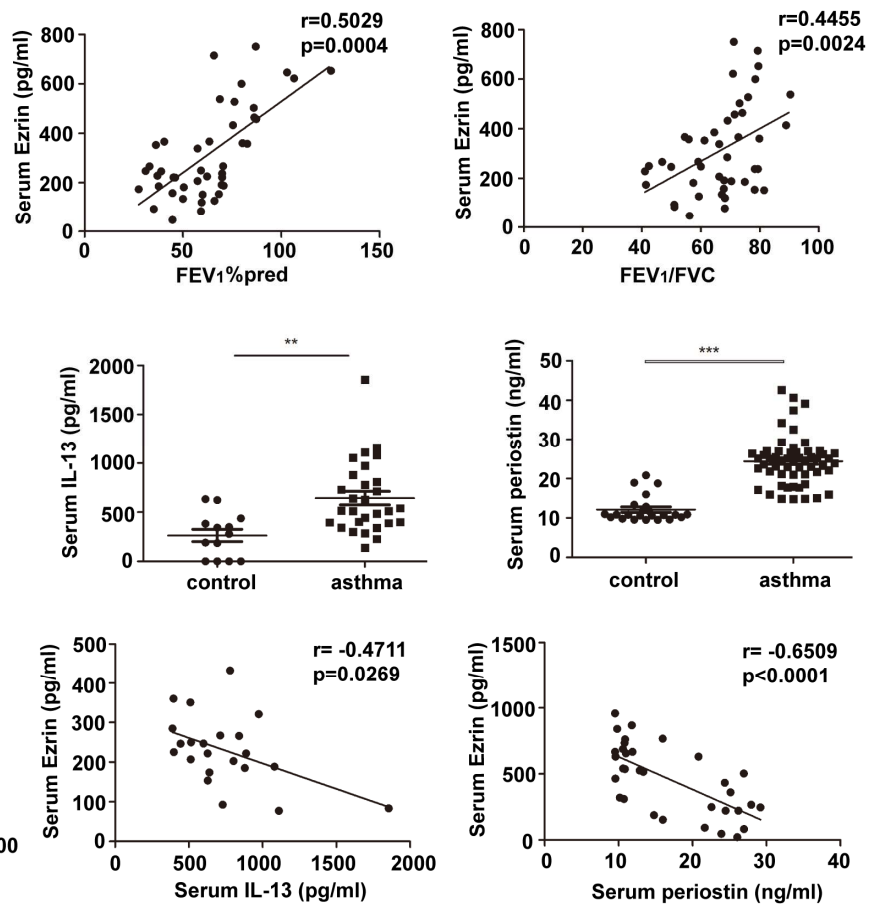


\section{Figure 3}

A
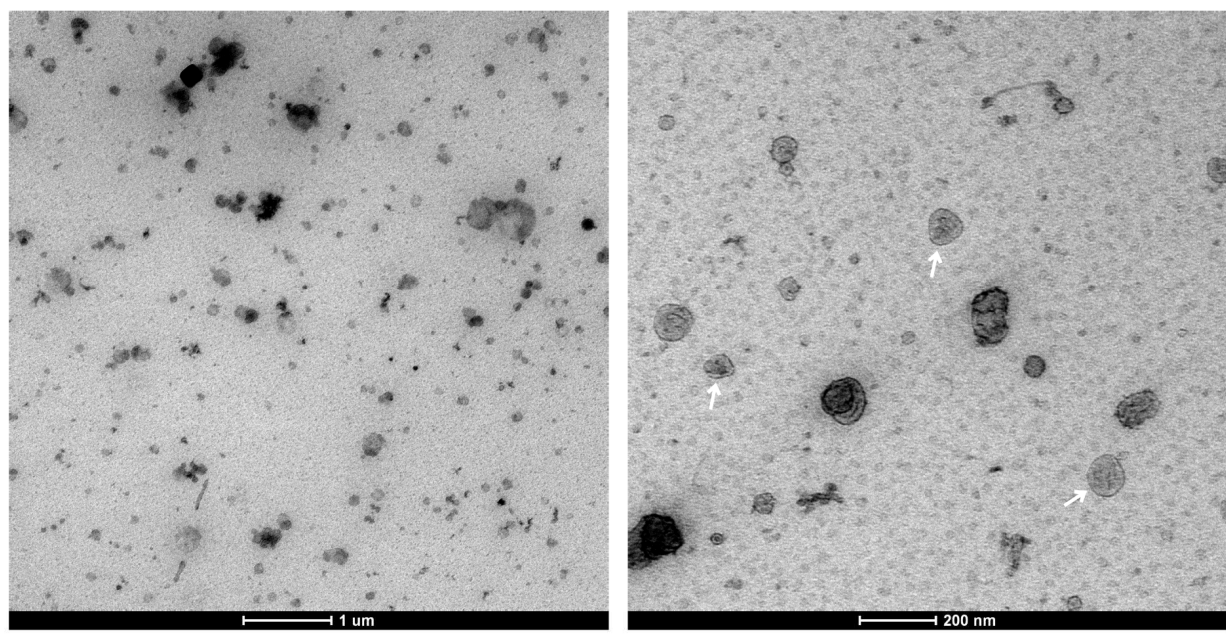

B

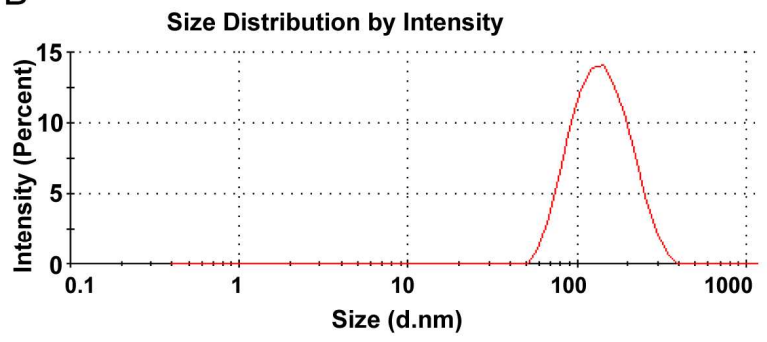

C

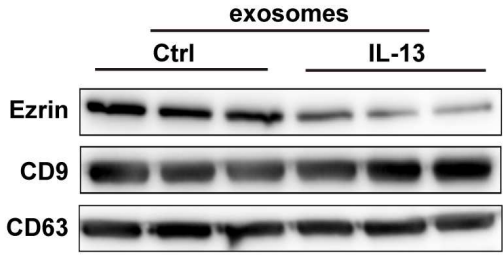

\begin{tabular}{|l|l|}
\hline Mean particle size $(\mathrm{nm})$ & 124 \\
\hline Peak particle size $(\mathrm{nm})$ & 147 \\
\hline Particle percentage $(20-200 \mathrm{~nm})$ & $84.3 \%$ \\
\hline
\end{tabular}


Figure 4

A

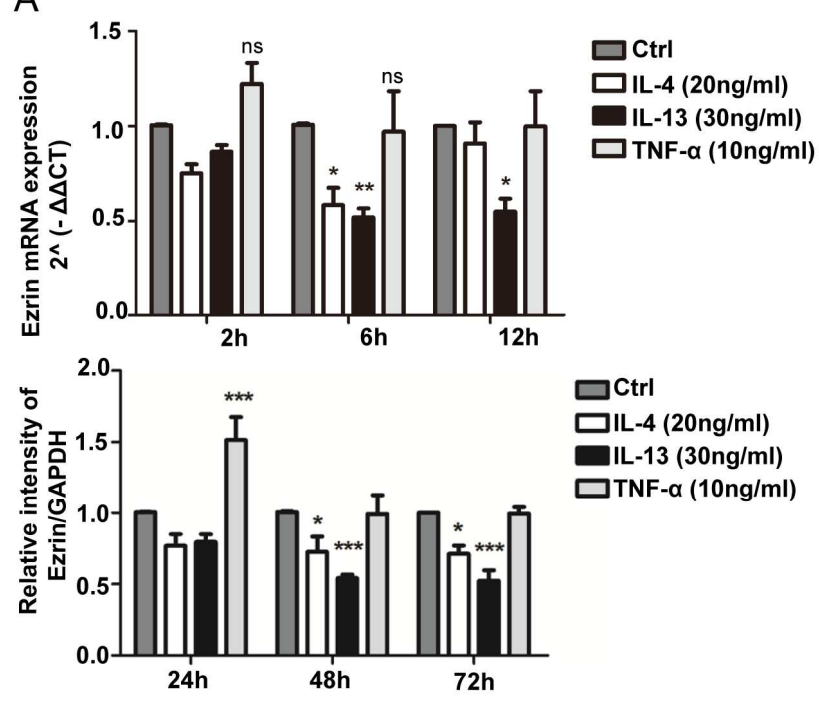

A

C
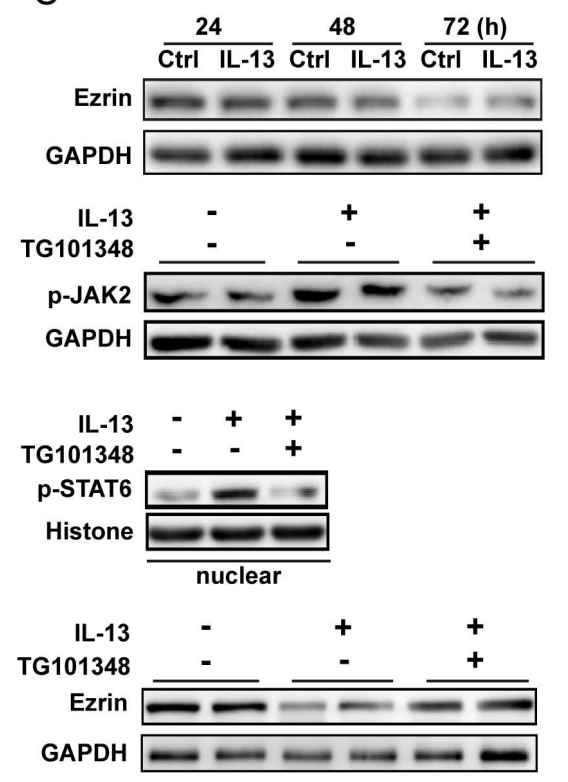
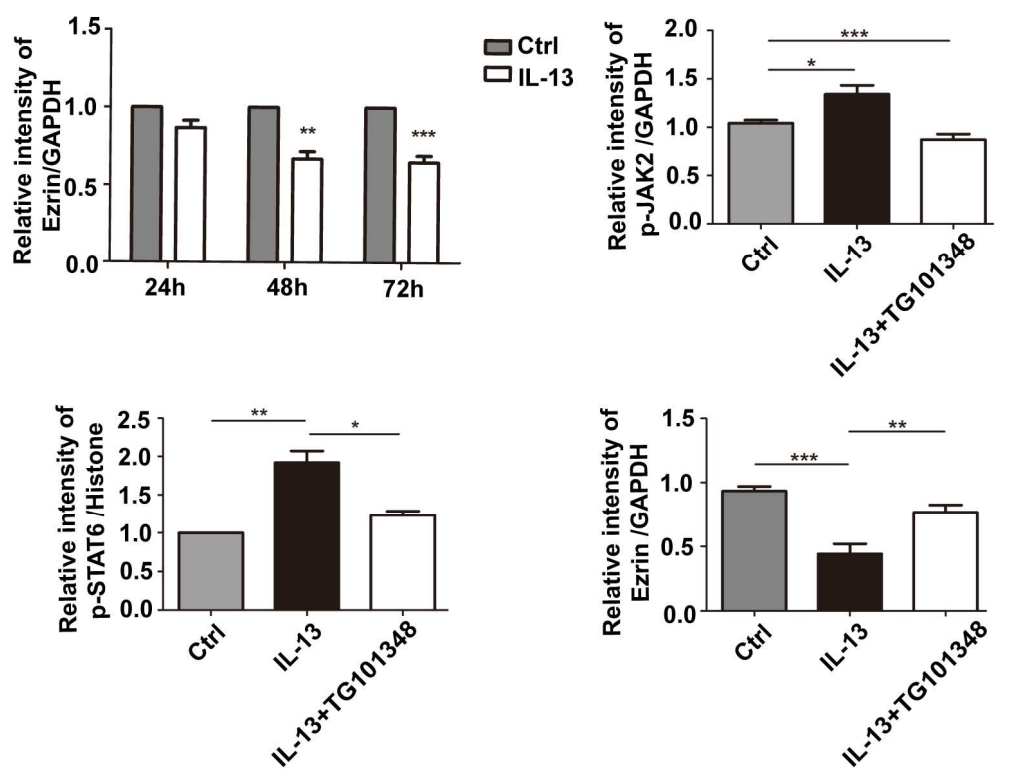

B
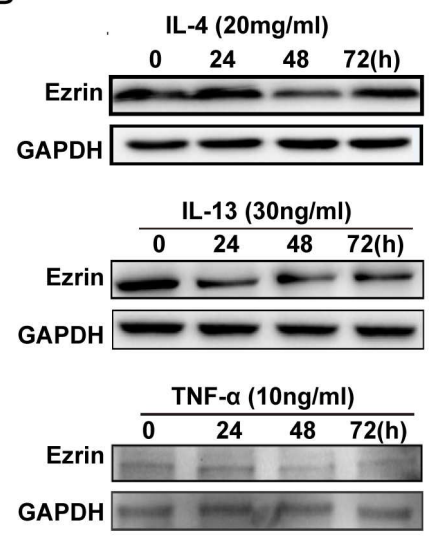
Figure 5
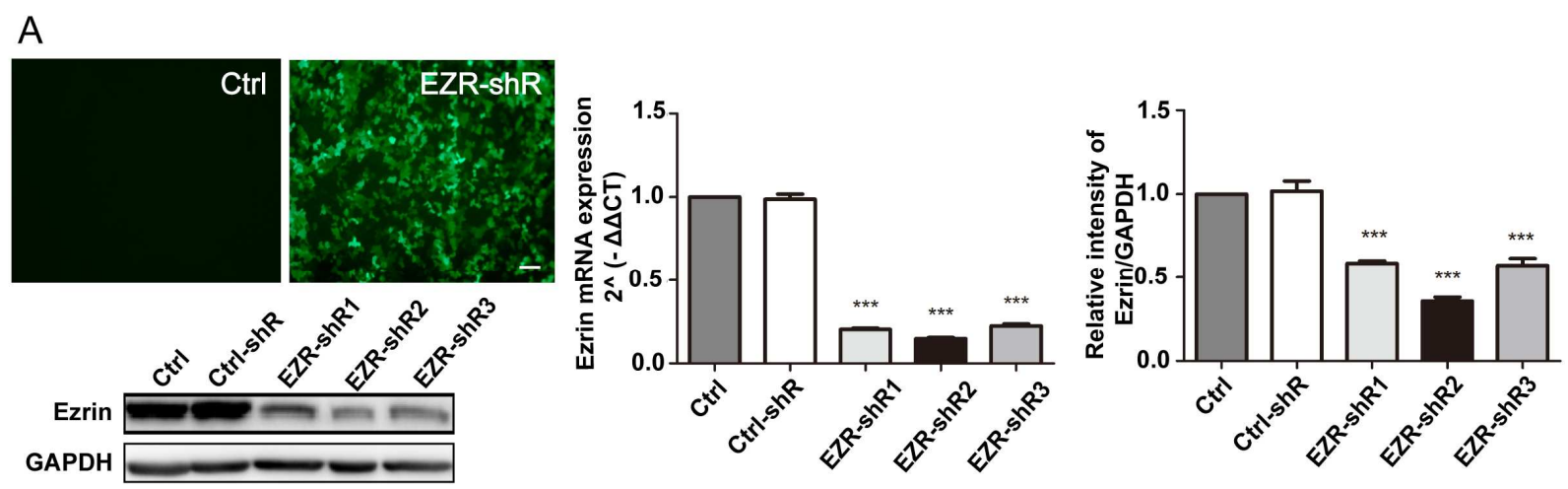

B

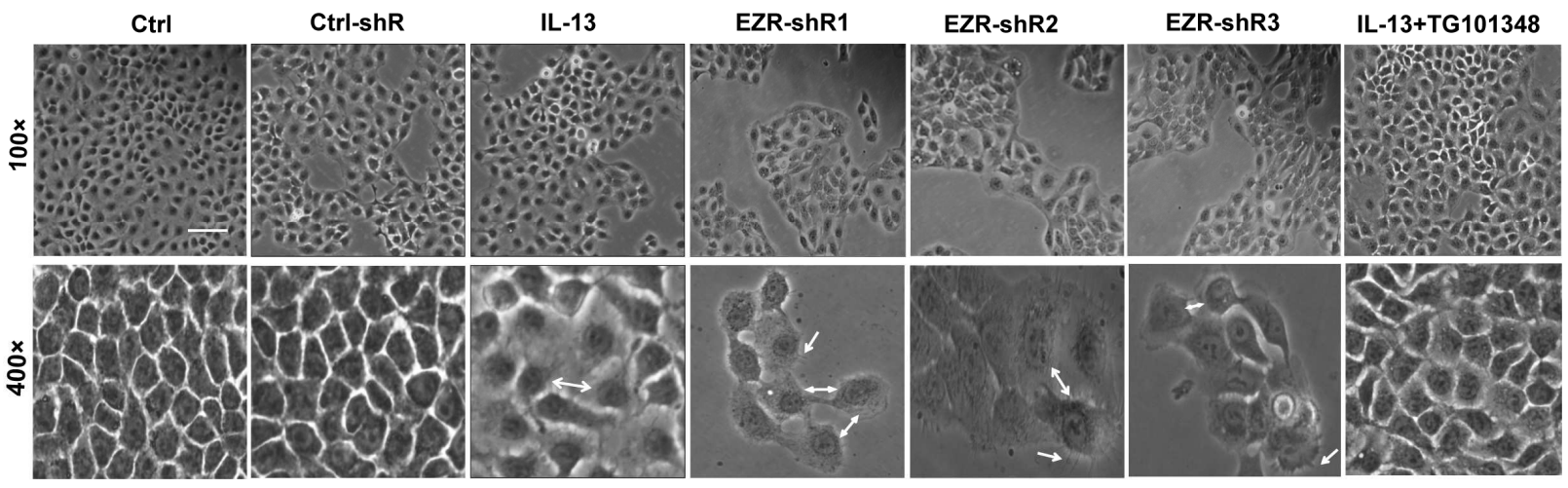

C
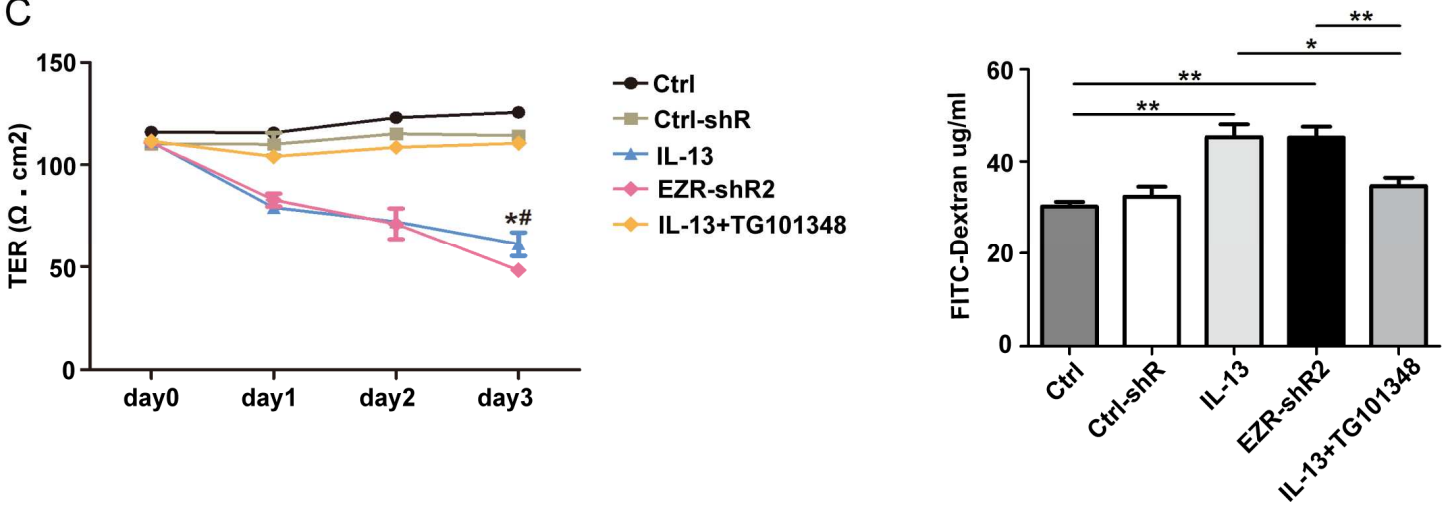
Figure 6

A
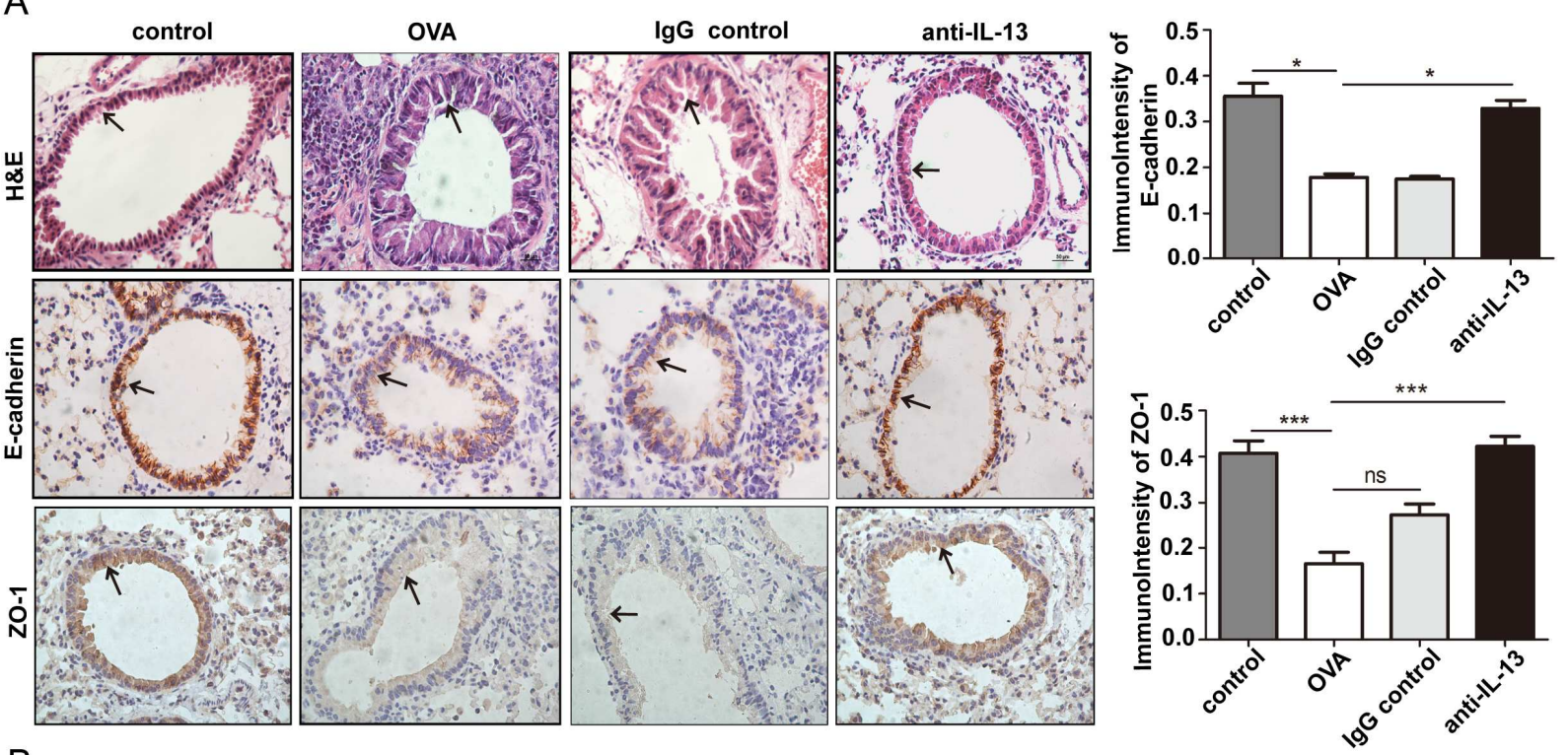

B

control

OVA

IgG control

anti-IL-13
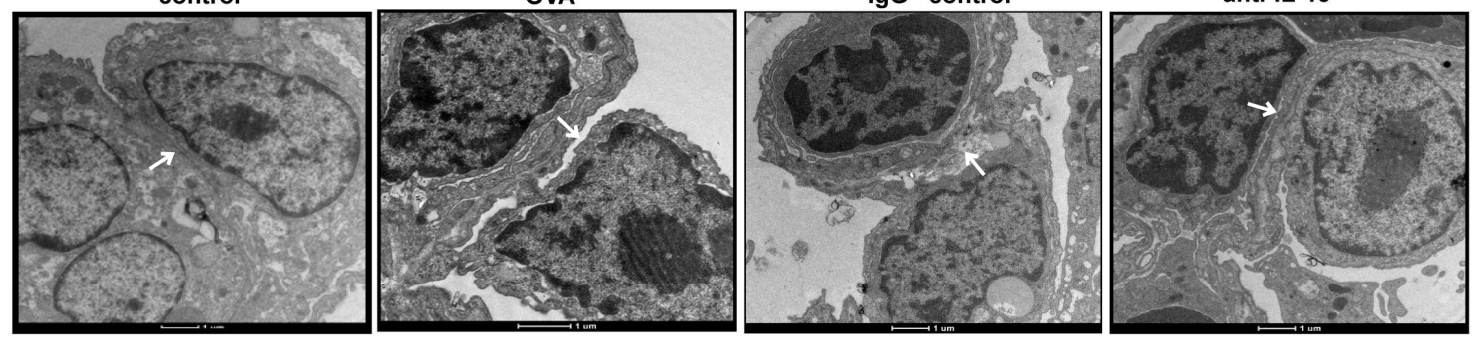

C

control

OVA

IgG control

anti-IL-13
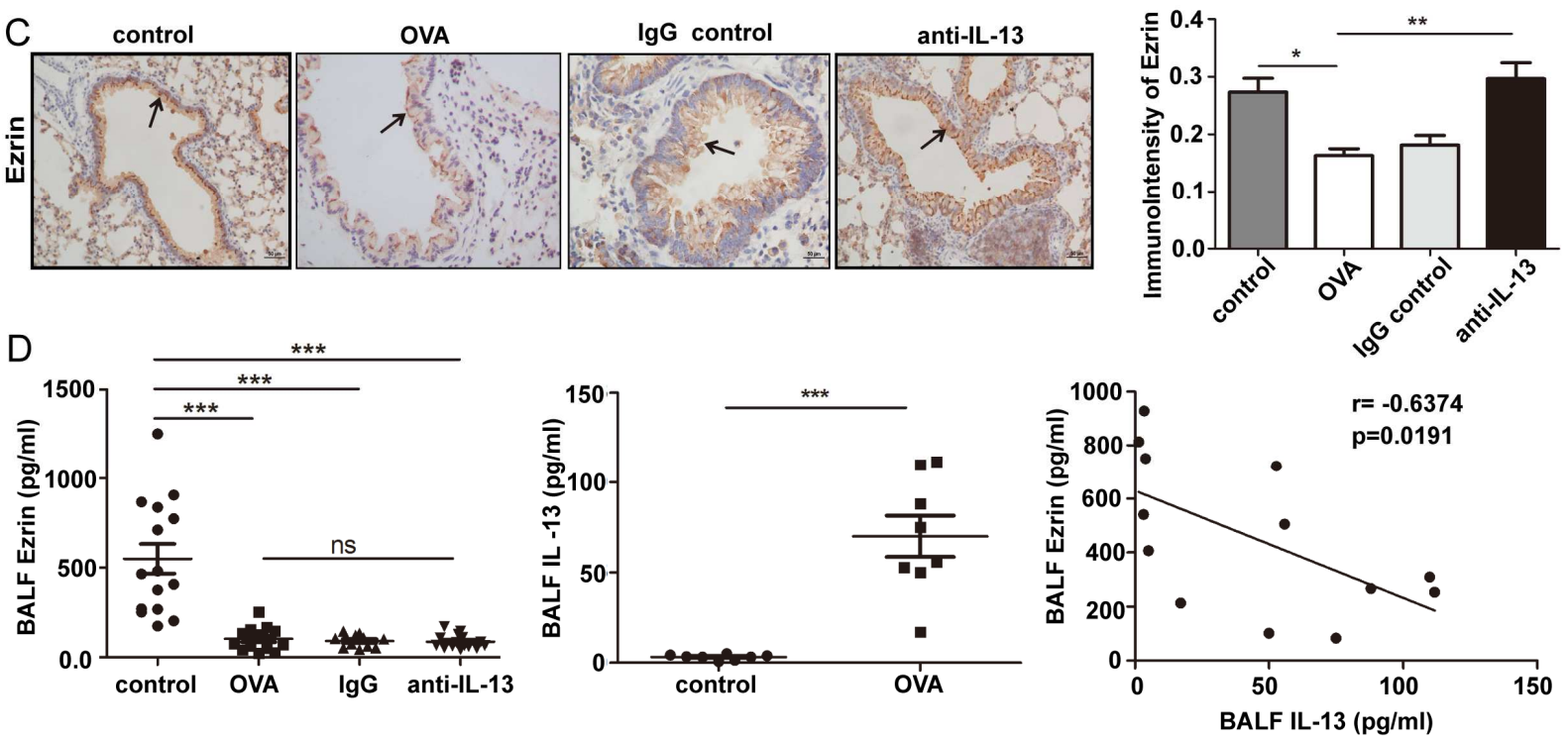


\section{Supplementary Materials and Methods}

\section{Ethics statement}

The protocol was approved by the ethics committee of The First Affiliated Hospital of Nanjing Medical University (2013-SRFA-037). Written informed consent was obtained from all patients. Animal experiments were performed under a Project License from the British Home Office, UK under the Animals (Scientific Procedures) Act 1986.

\section{Study subjects}

The diagnosis of bronchial asthma and severity of asthma were based on the Global Initiative for Asthma (GINA) guidelines [29]. Briefly, the severity of asthma was based on the level of asthma symptom control in the past 4 weeks. Patients were separated into those who had: 1) daytime symptoms $\geq$ twice per week; 2) nocturnal symptoms; 3) need for reliever treatment $\geq$ twice per week or 4) limitations in activities. Those with (1) or (2) were considered partly controlled and those with (3) or (4) were designated uncontrolled. In total 23 healthy subjects, 21 patients with well-controlled asthma, 17 patients with partly controlled asthma and 23 uncontrolled asthma patients were studied (Table 1). No patients had a history of lung cancer or chronic cardiopulmonary diseases. Healthy subjects had no history of asthma or any other chronic disease. All subjects were non-smokers and free from pulmonary infection in the 4 weeks before the study. There were no significant differences in gender, ages and BMI among the subject groups (Table 1). We followed-up 6 patients who were treated with the combination of low dose ICS (budesonide) and rapid-onset LABA (formoterol) in a single inhaler and recorded their lung function and symptom control. 


\section{Exhaled breath condensate (EBC) and serum collection}

Human EBC and serum samples were collected from respiratory outpatients with asthma of the First Affiliated Hospital of Nanjing Medical University, Nanjing Jiangning People's Hospital and Nanjing First Hospital and community healthy volunteers.

The EBC was collected by using an EcoScreen condenser (Jaeger, Wurzburg, Germany), which allowed for the noninvasive collection of nongaseous components of the expiratory air. Patients and control subjects were asked to breathe through a mouthpiece and a two-way nonrebreathing valve, which also served as a saliva trap, at a normal frequency and tidal volume, wearing a nose clip, for a period of 10 minutes (min). The condensate (at least $1 \mathrm{ml}$ ) was collected in ice at $4^{\circ} \mathrm{C}$, transferred to $1.5 \mathrm{ml}$ polypropylene tubes, and immediately stored at $80^{\circ} \mathrm{C}$ for the subsequent analysis [28]. Serum samples were isolated (by centrifugation at $3000 \mathrm{rpm}, 10 \mathrm{~min}$ within 2 hours) after whole blood collection, and the sera were kept at $40^{\circ} \mathrm{C}$ until they were assayed. Patient serum samples in (Figure 2C) were from the Unbiased Biomarkers for the Prediction of Respiratory Disease Outcomes (U-BIOPRED). Details on the selection of patients and data collection have been published previously [30]. The UBIOPRED study was registered at ClinicalTrials.gov (identifier: NCT01976767) and was approved by all Medical Ethics Boards. All patients provided written informed consent.

\section{Animal experiments}

BALB/c mice (6-8 weeks old, $20 \pm 0.7 \mathrm{~g}$ ) were randomly divided into four groups: control, ovalbumin (OVA), anti-IgG +OVA and anti-IL-13 +OVA. Protocols for the OVA-induced acute asthma model as well as an anti-IgG and an anti-IL-13 (30 $\mathrm{gg} / \mathrm{mouse})$ in allergic asthma model were as previously described [31-32] and were summarized in Figure S1A. Mice were 
sensitized by intraperitoneal injection with $4 \mathrm{ml} / \mathrm{kg}$ of the OVA-alum suspension $(2 \mathrm{mg} / \mathrm{kg}$ OVA and $80 \mathrm{mg} / \mathrm{kg}$ aluminum hydroxide) on days 0,7 , and 14 . Animals were anesthetize and challenged intranasally with the $4 \mathrm{mg} / \mathrm{ml}$ OVA solution by administering $12.5 \mu \mathrm{l}$ per nostril on days 21, 22 and 23 Saline challenge served as the control. The anti-IgG + OVA and anti-IL-13+ OVA groups were pretreated with Goat anti-Rabbit IgG antibody (Cat. No. RD AP132P) and Goat anti-Mouse IL-13 antibody

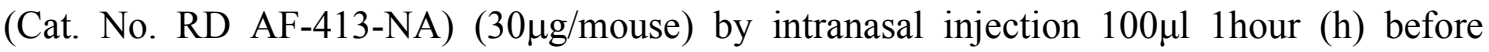
challenge with OVA on 3 consecutive days (days 21, 22 and 23). AHR was measured on day 24. Haematoxylin and eosin $(\mathrm{H} \& \mathrm{E})$ stained fixed lung tissues sections were used to assess inflammation: grade 0: no inflammatory cells; grade 1: few inflammatory cells; and grade 2,3,4: most bronchi or vessels which were surrounded by a thin layer (1-2 cells: grade 2$)$, a moderate layer (3-5 cells: grade 3 ), or a thick layer ( $>5$ cells: grade 4$)$ of inflammatory cells, respectively, by microscope (Nikon, Tokyo, Japan) at $400 \times$ magnification. The total inflammatory score was calculated as the average of all individual inflammatory scores. Bronchial alveolar lavage fluid (BALF) were collected within $24 \mathrm{~h}$ after the last exposure and stored at $-80^{\circ} \mathrm{C}$.

\section{Immunohistochemical staining}

Mouse lung tissues were stained with a rabbit monoclonal anti-mouse ezrin antibody (Cat. No. CST 3145S; Cell Signalling Technology Inc., Beverly, MA, USA) (1:100 dilution), a rabbit monoclonal anti-mouse E-cadherin antibody (Cell Signalling Technology Inc., Beverly, MA, USA) (1:100 dilution), a rabbit polyclonal anti-mouse ZO-1 antibody (Proteintech Group Inc, China) (1:100 dilution). The sections were developed using a DAB substrate kit (Thermo Fisher Scientific, Massachusetts, USA). The results were quantified with Image-Pro Plus. 


\section{Cell culture and lentivirus shRNA gene transfection}

Primary human bronchial epithelial cells (PBECs) were purchased from the ScienCell Research Laboratories (Carlsbad, CA, USA), and were cultured in bronchial epithelial cell medium (BEpiCM; ScienCell Research Laboratories) containing bronchial epithelial cell growth supplement, $100 \mathrm{mg} / \mathrm{ml}$ penicillin and $100 \mathrm{U} / \mathrm{ml}$ streptomycin $1 \%$ antibiotics (ScienCell Research Laboratories) according to the manufacturer's instructions. PHBECs were serially passaged and used for experiments until passage 5 and seeded in cell culture plates with a seeding density of $1 \times 10^{5}$ cells $/ \mathrm{cm}^{2}$.

The human bronchial epithelial cell line (16HBE cells) was obtained from the Beijing Tumor Center. Cells were maintained in RPMI 1640 (ATCC) with 10\% fetal bovine serum (FBS, ScienCell, San Diego, CA,USA) and 1\% penicillin/streptomycin(Gibco, Grand Island, NY, USA) at $37^{\circ} \mathrm{C} / 5 \% \mathrm{CO}_{2}$ [22]. Cells were transfected with lentiviruses encoding for a control shRNA or human Ezrin-shRNA targeting GFP according to the manufacturers' instructions. The lentiviruses were diluted in enhanced infection solution $(10 \mathrm{mg} / \mathrm{mL})$ containing polybrene (5ug/ml) and added to the cells at $37^{\circ} \mathrm{C}$ for $24 \mathrm{~h}$ and freshly prepared complete medium. A fluorescence microscope (Nikon, Tokyo, Japan) was used to observe the effect of transfection and cell morphology was recorded for the next $48 \mathrm{~h}$.

\section{Exosomes isolation and Nanoparticle tracking analysis (NTA)}

$16 \mathrm{HBE}$ cell supernatants were centrifuged at $300 \times \mathrm{g}$ for $10 \mathrm{~min}, 2000 \times \mathrm{g}$ for $10 \mathrm{~min}$, and at $10000 \times \mathrm{g}$ for $30 \mathrm{~min}$ in turn with the supernatant being retained at each step. The supernatant was then centrifuged at $100000 \times \mathrm{g}$ for $70 \mathrm{~min}$ and the pellet retained. The pellet was resuspended in PBS before being centrifuged again at $100000 \times \mathrm{g}$ for $70 \mathrm{~min}$. Particle 
suspensions were diluted with PBS and were analyzed by nanoparticle tracking, using a ZETASIZER Nano ZS apparatus (Malvern Instruments, Worcestershire, UK).

\section{Transmission electron microscopy (TEM)}

Samples (exosomes and ultra-thin sections of mouse lung tissue) were prepared as described previously [35-36] and were photographed under a TEM (JEOL-1010, Jeol, Tokyo, Japan).

\section{Enzyme-linked immunosorbent assay (ELISA)}

The levels of IL-4 (M400B), IL-5 (M5000), and IL-13 (DY413) in mouse BALF were measured by ELISA kit according to manufacturer's instructions (R\&D, Minneapolis, MN, USA). The levels of ezrin in human samples were detected by human ELISA kits (SEB297Hu, Cloud Clone Corp, Wuhan, China). The detection range was $0.312 \mathrm{ng} / \mathrm{ml}-20 \mathrm{ng} / \mathrm{ml}$ with the minimum detectable concentration of ezrin differentiated from zero being $0.117 \mathrm{ng} / \mathrm{ml}$. Ezrin levels in murine BALF were detected by specific anti-mouse ELISA (CSB-EL007914MO, Cusabio, Wuhan, China). The detection range was $62.5 \mathrm{pg} / \mathrm{ml}-4000 \mathrm{pg} / \mathrm{ml}$ with minimum detectable concentration of ezrin compared to zero being $15.6 \mathrm{pg} / \mathrm{ml}$. Human serum IL-13, periostin and IgE were measured respectively using human IL-13 ELISA kit (CSB-E0460, Cusabio, Wuhan, China), human periostin ELISA kit (SEH339Hu, Cloud Clone Corp, Wuhan, China) and human IgE ELISA kit (BMS2097, Raybiotech, USA) according to manufacturer's protocols. All samples were within the detectable range of each assay. The absorbance was measured at 450nm using a model 550 microplate reader (Bio-Rad, Hercules, CA, USA). 


\section{Western blot analysis}

Cell proteins were extracted using RIPA lysis buffer with protease inhibitors (Beyotime, China). Nuclear protein was extracted using NE-PER ${ }^{\mathrm{TM}}$ Nuclear and Cytoplasmic Extraction Reagents (ThermoFisher, Waltham, USA). $20 \mu \mathrm{g}$ protein was separated by $10 \%$ SDS-PAGE and transferred to PVDF-membranes (Millipore, Bedford, MA). The primary rabbit antibodies used were anti-ezrin (1:1000) (Cell Signaling Technology, US), anti-p-JAK2 (1:1000) (Proteintech Group Inc, China), anti-P-STAT6 (Proteintech, Group Inc, China), antiGAPDH (1:1000) (Cell Signaling Technology, US) and anti-Histone (Cell Signaling Technology, US). Membranes were blocking in 5\%BSA for $1 \mathrm{~h}$ at room temperature before incubation with primary antibody at $4{ }^{\circ} \mathrm{C}$ overnight. Membranes were washed three times in TBST and then incubated with HRP-linked anti-Rabbit IgG secondary antibody (1:5000) (Bioworld, Shanghai, China) at $20^{\circ} \mathrm{C}$ for $1 \mathrm{~h}$. The blots were visualized with an ECL plus reagent (ECL, Thermo Scientific, Waltham, USA).

\section{RNA extraction and real time PCR (RT-qPCR)}

RNA was extracted using Trizol reagent (Invitrogen, Carlsbad, CA) according to the manufacturer's protocol. Total RNA $(1 \mu \mathrm{g})$ was reverse transcribed using PrimeScript TM Reverse Transcriptase (Takara, Kyoto, Japan) and quantitative real-time PCR was performed using SYBR qRCR premix (Takara, Kyoto, Japan). The specific sequences of forward (F) and reverse $(\mathrm{R})$ primers used are as follows:

Human GAPDH: $\quad$ Forward Primer 5'-AGAAGGCTGGGGCTCATTTG-3'

Reverse Primer 5'-GGGGCCATCCACAGTCTTC-3'; 
Human Ezrin: $\quad$ Forward Primer 5'- ACCAATCAATGTCCGAGTTACC-3'

Reverse Primer 5'- GCCGATAGTCTTTACCACCTGA-3';

Cycling conditions were an initial denaturation at $95^{\circ} \mathrm{C}$ for 30 seconds (sec), followed by 40 cycles at $95^{\circ} \mathrm{C}$ for $5 \mathrm{sec}, 60^{\circ} \mathrm{C}$ for $30 \mathrm{sec}$, and $72^{\circ} \mathrm{C}$ for $10 \mathrm{~min}$. Data was normalized using the $\Delta \Delta \mathrm{CT}$ method.

\section{Measurement of transepithelial electrical resistance (TER) and epithelial permeability}

16HBE cells were seeded in 24-well Transwell (Corning Costar, NY, USA) inserts and allowed to grow until fully integrated into a single layer. TER was measured daily using the Millicell-ERS system (Millipore Co., Bedford, MA, USA) [37]. 100ul RPMI-1640 containing $0.5 \mathrm{mg} / \mathrm{mL}$ fluorescein isothiocyanate (FITC)-labelled dextran (Sigma Chemical Co.; molecular weight $40 \mathrm{~K} \mathrm{Da}$ ) was added to the apical compartments (luminal side). 500uL RPMI-1640 without FITC-labelled dextran was added to the basal compartments (nonluminal side), and the plates were incubated at $37^{\circ} \mathrm{C}$ for $90 \mathrm{~min}$. Samples from the apical and basal compartments were analyzed in black 96 well plates by multimode reader. Excitation and emission wavelengths were 490 and $520 \mathrm{~nm}$, respectively.

\section{Statistical analysis}

All data are presented as mean $\pm \mathrm{SEM}$ and $\mathrm{P}<0.05$ was considered significant. The statistical analyses were performed using GraphPad Prism software v5.0 (GraphPad Software, Inc., San Diego, California, USA). Experiments with multiple comparisons were evaluated by one-way 
ANOVA followed by Student-Newman-Keuls post-test or Bonferroni's post-test (normally distributed parameters) and Kruskal-Wallis test (non-normal distributed parameters) for multiple data sets. Comparisons between two groups were performed with an unpaired Student's t test for normally distributed parameters and with Wilcoxon rank-sum test for nonnormal distributed parameters.

\section{Supplemental Figure Legend}

\section{Figure S1. The establishment of an ovalbumin (OVA) induced allergic asthma and an} anti-IL-13 in allergic asthma model. (A) A scheme of the development of the mouse model and the airway resistance of saline-exposed control animals (control), OVA-treated animals (OVA), OVA+anti-IgG antibody animals (anti-IgG) and ONA+anti-IL-13 antibody treated animals (anti-IL-13). (B) An overall inflammatory score was calculated to indicate the degree of inflammatory cell infiltration ( $\mathrm{n} \geq 6 /$ group). (C) The total cell number and cell type in BALF of OVA-treated 'asthma' mice $(\mathrm{n}=10)$ and OVA+anti-IL-13 antibody treatment mice $(\mathrm{n}=10)$. (D) Levels of IL-4 (control mice, $\mathrm{n}=12$; 'asthma' mice, $\mathrm{n}=11$ ) and IL-5 (control mice, $\mathrm{n}=8$; 'asthma' mice, $\mathrm{n}=8$ ) in BALF of asthma mice by ELISA. Data is shown as mean $\pm \mathrm{SD},(\mathbf{B})$ and (C) were analyzed using one-way ANOVA followed by Bonferroni's post hoc analysis. (D) were analyzed using Student's t-test. ${ }^{*} \mathrm{P}<0.05$ (OVA VS control), ${ }^{\#} \mathrm{P}<0.05$ (OVA VS antiIL-13) in (A). $* \mathrm{P}<0.05, * * \mathrm{P}<0.01$ and $* * * \mathrm{p}<0.001$ compared to respective controls. 


\section{Figure S1}

A

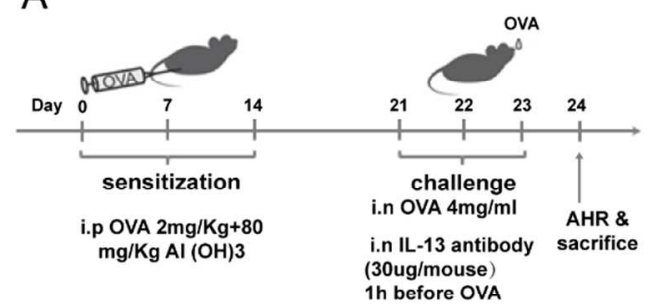

C

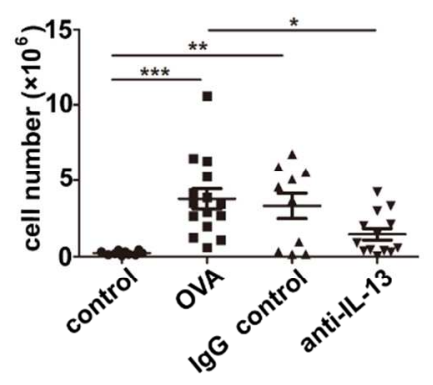

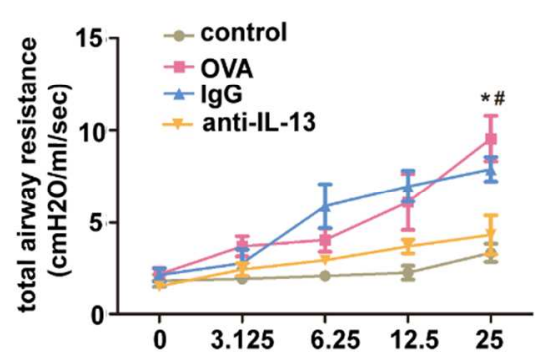

D
B
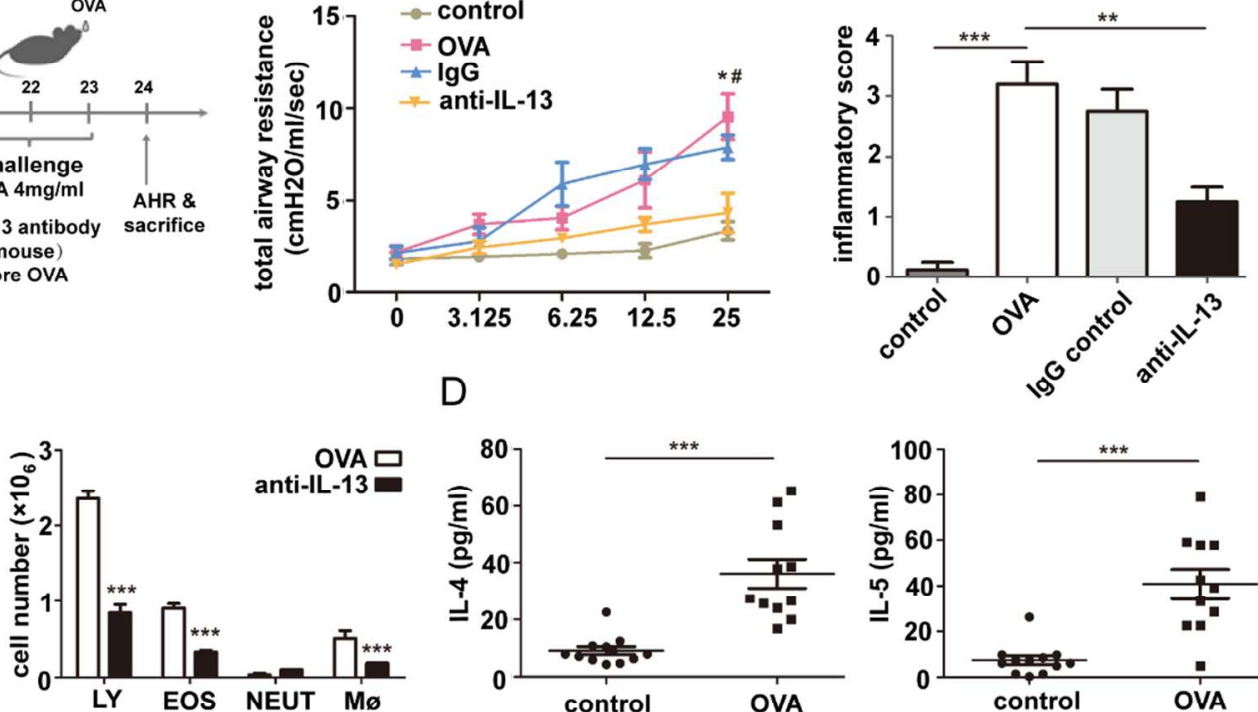
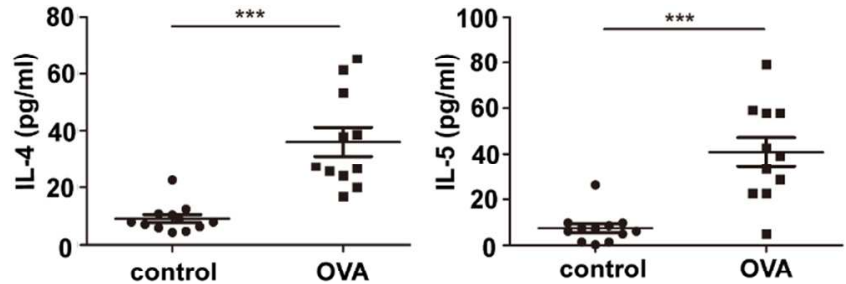